\title{
Remote and Blended Teacher Education: A Rapid Review
}

\author{
Thomas Perry ${ }^{1, *} \mathbb{C}$, Madeleine Findon ${ }^{1}$ and Philippa Cordingley ${ }^{2}$ \\ 1 Department of Teacher Education, University of Birmingham, Birmingham B15 2TT, UK; \\ m.a.findon@bham.ac.uk \\ 2 Centre for the Use of Research \& Evidence in Education (CUREE), Penrith CA10 3HN, UK; \\ philippa.cordingley@curee.co.uk \\ * Correspondence: t.w.perry@bham.ac.uk
}

Citation: Perry, T.; Findon, M.; Cordingley, P. Remote and Blended Teacher Education: A Rapid Review. Educ. Sci. 2021, 11, 453. https:// doi.org/10.3390/educsci11080453

Academic Editors: Beng Huat See and Rebecca Morris

Received: 30 April 2021

Accepted: 2 August 2021

Published: 23 August 2021

Publisher's Note: MDPI stays neutral with regard to jurisdictional claims in published maps and institutional affiliations.

\begin{abstract}
Initial and continuing teacher education are increasingly making use of remote and blended modes of education. Conducted in the summer of 2020 during the COVID-19 pandemic, this rapid review brings together literature and evidence to inform planning for remote and blended teacher education during restrictions in face-to-face teaching activity. The review consists of three main parts: first, a descriptive framework of modes of remote and blended teacher education; second, an exploratory review of the affordances and limitations of remote and blended approaches connecting the literature on effective teacher education with reviews of remote and blended approaches; third, a rapid review of evidence on the efficacy of remote and blended approaches, including of a small number of studies comparing these to face-to-face equivalents. We conclude that remote and blended teacher education is likely to become an increasingly important part of the teacher education landscape and there are plausible theoretical reasons suggesting that it can be effective with suitable design. However, we find too few studies presenting robust evidence to enable firm conclusions to be drawn on the relative effectiveness of modes and approaches. The review provides a foundation for further research and practice in this area.
\end{abstract}

Keywords: teacher education; professional development; remote learning; rapid review

\section{Introduction}

\subsection{Remote and Blended Teacher Education}

It is widely acknowledged that teacher quality is the largest single factor affecting student achievement that is amenable to school and policy influence (Slater et al., 2012; Kane et al., 2013) [1,2]. Teacher education, including initial education and continuing professional development (CPD), is therefore arguably the most direct, effective, and costeffective approach to school improvement (Fletcher-Wood and Zuccollo, 2020) [3]. Here, we define initial teacher education as any training provided to pre-service teachers as part of qualification; we define continuing professional development as any support or training for in-service teachers. In both cases our focus is on efforts to improve teacher effectiveness. We know it is possible to improve teacher effectiveness (Kraft and Papay, 2014; Hill et al., 2020) $[4,5]$, and that there are also wider benefits of doing so including greater collective teacher efficacy (Tschannen-Moran and Hoy, 2001) [6], wellbeing, retention and recruitment, in particular for early-career teachers (Fletcher-Wood and Zuccollo, 2020; Cordingley et al., 2019) [3,7]. The literatures on effective initial teacher education and CPD have not to date been well connected to those on blended and online teacher education; a contribution of this review is to make this connection, bringing together theory, evidence and description of practice for remote and blended teacher education (see Section 1.2, below for further details).

There is ongoing debate about the definitions of 'remote', 'distance' and 'blended' modes of education (Hobbs and Bolan, 2021) [8]. Accordingly, another contribution of this review is the development of a two-part, mode-characteristics framework which 
can be used to describe forms of teacher education other than face-to-face provision. Prior to presenting this, we proceed on the basis of simple, broad definitions: we define remote teacher education as any mode other than face-to-face education, typically but not necessarily conducted online (i.e., using computers, tablet devices, smart phones and other web-based technologies). We define blended teacher education as a combination of face-to-face and remote education in any proportion. As we discuss at length in the substantive sections of this review, there is a large amount of variation across and within approaches to teacher education which fall under these broad definitions.

This review is timely. In recent decades, as technology has developed, organizations providing initial and continuing professional development for classroom teachers have increasingly developed blended learning offers, combining distance with face-to-face provision of professional learning content and activities. This slowly increasing trend towards distance and blended forms of teacher education has accelerated rapidly in the context of COVID-19, leading many providers to review their offer in terms of which modes are available for components and content areas in their programs and provision (La Velle, Newman, Montgomery, and Hyatt, 2020) [9]. In our own experience of initial teacher education provision, for instance, teacher educators have had to rapidly prepare and deliver online provision to enable students to continue with their education, and to enable finalists to be recommended for Qualified Teacher Status. Online provision has included video and voice-over to supplement PowerPoint presentations, video-capture lesson recordings, discussion boards, and virtual learning environment chat rooms to ensure that students' knowledge and skills continue to develop while face-to-face contact was not possible.

There is a long history of using blended learning for teacher education, in particular in developing and developed countries (e.g., see Burns, 2011, discussing initial teacher education) [10] and in locations where face-to-face provision presents challenges. In such cases, wireless education for teachers is a venerable forerunner of remote and blended CPD. Australia, for example, has a particularly long history of trying to meet CPD and teacher education needs remotely because of its topography. Dyment and Downing (2020, p.316) [11] report that 'between 2005 and 2016, the number of initial teacher education (ITE) students choosing an online or blended mode of study in Australia nearly doubled from 5412 (22\% of total) in 2005 to 12,143 (41\% of total) in 2015 (Australian Institute for Teaching and School Leadership (AITSL), 2015) [12]. Of the 47 providers of ITE in 2015 in Australia, $19(40 \%)$ offered some or all of their courses in an online or blended mode of study.' This increase in remote and blended provision is also reflected in the academic literature, with Dyment and Downing being struck by the exponential increase in material when preparing their review in 2019, as compared to a 2013 review. Similarly with the literature on remote and blended continuing professional development: back in 2009, Dede et al. (2009) described much of the literature in the field of online teacher professional development as 'anecdotal', urging researchers to work towards an 'evidence-based conceptual framework that provides robust explanatory power for theory and model building' [13] (p. 8). Five years later, Fishman et al. (2014a, p. 261) [14], were agreeing with Moon et al. that "the field would benefit from scholarship that leads to 'research-based design principles to guide the ongoing development, implementation, and evaluation efforts in online PD (Moon et al., 2014, p. 1) [15]'". Now, another 6 years (and a global pandemic) later, this rapid review takes another look at the approaches, affordances and evidence on remote and blended initial and continuing teacher education. At present there is not an established systematic review focused specifically on effectiveness of or within modes of teacher education. Our initial scoping suggested that the evidence base in this area would be disparate, and there would likely be challenges applying it to a COVID-19 or post-COVID-19 scenario. With few common definitions and considerable variation in practices, we also anticipated challenges delineating between modalities that blend face-to-face and online modes. Nonetheless, we set out to identify relevant studies with the potential to provide practical theory and an evidence base for effective remote and blended teacher education practice. We also 
revisited existing teacher education reviews and meta-analyses with a specific focus on identifying evidence and implications relevant to teacher education modality.

\subsection{Review Aims, Questions and Contribution}

This review was conducted during the summer 2020. It had the specific immediate aim of informing the research and commissioning organizations' teacher education provision for the new academic term beginning in September. The time available of around 4-6 weeks, the commitment of both organizations to evidence-informed practice, and the value of identifying principles for action all necessitated a broad range of literature being brought together in a very limited time frame. As such, we describe the study as a rapid review. As discussed in the methods section, in part this consisted of a simplified, systematic review prioritizing the identification of robust trials of remote and blended teacher education trials (reported in Section 5). Given our broader, practical aims, we also located reviews and empirical studies that describe remote and blended teacher education and/or reported principles for their effective design. While our treatment of these employed elements of systematic review approaches to minimize bias and increase transparency, the time and resource constraints did not allow a wholly systematic treatment. Accordingly, we have described these sections (Sections 3 and 4) as 'exploratory'; our aim with these sections is to bring together, summarize and interpret a large range of literature on CPD, teacher education and remote and blended modes of teacher education into a single account that addressed the immediate aim of informing current provision as well as providing a foundation for further research in this area.

In overview, this rapid review report consists of the following four sections, each with a specific aim and set of questions. We describe the methods employed within these four sections in Section 2 below.

\section{Section 3-Remote and Blended Teacher Education Modes and Their Characteristics}

Approaches-What forms of/approaches to remote or blended teacher education have been explored in the research literature? What are their typical characteristics/elements? How can this be organized?

In this section, we summarised reviews and empirical pieces in our data base that described specific modes and approaches to remote and blended teacher education, either individually or with a view to providing an organizing conceptual framework. We synthesize descriptions and frameworks to present our own two-part typology (modescharacteristics) framework, which we proceed to provide illustrative examples for.

\section{Section 4-Affordances and Limitations of Remote and Blended Approaches to Teacher Education}

Affordances and Limitations-What are the affordances and limitations of remote and blended teacher education relative to face-to-face variants? What adaptations, restrictions or enhancements are typical relative to face-to-face variants?

a. What, from a theoretical standpoint, can be inferred from the literature on effective continuing professional development and learning (CPDL) and initial teacher education (ITE)?

b. What is advocated as best practice in the remote/blended teacher education literature?

This section examines the theoretical and practical principles behind effective remote and blended teacher education. It does this by organizing, summarizing and analyzing reviews and empirical studies in our database against a set of principles for effective CPD and ITE. We present these principles for effective CPD and ITE in Sections 1.3 and 1.4, respectively, below. By connecting the literature on effective remote and blended provision with a framework for effective CPD and ITE, we are able to present an exploratory but evidence-informed account of the affordances and limitations of conducting teacher education through remote modes. This provides theoretical support for the use of remote modes, identifies adaptations recommended in the literature and in some cases identifies advantages of remote education over face-to-face alternatives. 


\section{Section 5-Review of Empirical Evidence}

Evidence-What empirical evidence is available that supports, refutes and/or refines our understanding of effective remote or blended teacher education (as per Q2)?

a. Which forms or practices are identified as more/less effective?

b. What are the common features of effective approaches?

In Section 5, we present the evidence from trials of remote and blended teacher education that we have systematically reviewed. This is a subset of the overall review database which consists of studies employing appropriate research designs for causal estimates of the impact of remote or blended teacher education interventions on pupil outcomes. We also report a very small subset of these studies that compare the effect of remote or blended teacher education interventions against comparable, face-to-face alternatives. Given the limitation in this evidence base, our findings are restricted to a more general judgements of the effectiveness of remote and blended teacher education. We have presented our original, more granular, questions above for purposes of transparency in relation to our original aims, despite the limitations of the final evidence base.

\section{Section 6-Conclusions}

Implications and Unknowns-What, if any, general principles for effective online or blended teacher education are evident?

a. What does the evidence suggest about the relative effectiveness of teacher education modalities (including in comparison with the face-to-face mode)?

b. What are the main areas of uncertainty and gaps in our present understanding?

We have organized the overall paper to provide discussions and summaries of findings in each of the substantive sections above. Section 6, therefore, provides a short, more general conclusion and reflections on the present state-of-the-art in the research and practice of remote and blended teacher education.

\subsection{Effective Continuing Professional Development and Learning}

Whether teacher education is supported face-to-face, online or through a blend of both modes of activity, it is important for us start with some clarity about the key elements of success likely to applicable to all modes. We therefore consider in this section the principles for effective CPD and then additional considerations and differences for initial teacher education. As we describe above, this provides a conceptual framework for Section 4, where we consider the affordances and limitations of remote and blended teacher education. This connection between the general CPD literature and the remote and blended teacher education literature reflects our assumption that understanding effective remote and online teacher learning requires one to apply what is already known about effective teacher education to a new space, and while utilizing new technologies (Quinn et al., 2019) [16]. In other words, we hold that should not be confusing the medium (and the structure) for the message: Whether online, face-to-face or a blend of these, teachers must go through a familiar set of thinking and practice development processes. Insofar as there are separate principles for effective blended and remote teacher learning, they will relate to how we can employ new approaches, mitigate their limitations, and realize their affordances in recognition of the more general set of teacher learning principles.

In Table 1, below, we provide an overview of principles for effective CPD, continuing professional development learning (CPDL) leadership and then initial teacher education. CPDL is a broader concept than CPD which includes the learning (L) from CPD and ongoing professional learning connected, or in addition, to formal training and development (CPD) activity (Cordingley, 2015) [17]. For leadership of CPDL, we include all staff within educational organizations who have a role or influence on professional development; typically those in senior leadership positions and/or with formal responsibilities relating to professional development. Key reviews sitting behind these principles include those conducted by Cordingley et al. (2015, 2018, and 2020) [18-20], led by the Centre for the Use 
of Research and Evidence in Education (CUREE). We have also consulted several other reviews of effective CPD, all with their own foci in areas of teacher education, locations and review methodologies. All reviews of professional development consulted are included in the dedicated section of the review references. Of particular note in terms of both quality and recency are the Darling-Hammond (2017) [21] review, assessing studies employing experimental or quasi-experimental designs for teacher development; the Rogers, Brown and Poblete (2020) [22] systematic review focusing on professional learning in early years of education; and the meta-analysis from Hill et al. (2020) [5] which briefly summarizes effective professional learning in relation to STEM-focused programmes.

Table 1. Overview of Principles for Effective CPD and its Leadership.

\section{Summary of Research on Key Elements of Effective CPD}

- $\quad$ Pupil orientation - organising CPDL around colleagues' aspirations for pupils including outcomes,

- Diagnostics-identification and understanding of teachers' starting points (professional identities practices and motivations, beliefs, approaches to learning, existing knowledge and skills and beliefs),

- Differentiation - tailoring of learning experiences to teachers' starting points,

- Theory and practice-emphasizing practical theory alongside content and pedagogy,

- Collaboration/peer support-ensuring this originates from iterative trialling and testing of new approaches and evidence about how pupils' respond to accelerate trust, deepen ownership, and refine practice,

- $\quad$ Specialist expertise-mobilising and integrating deep knowledge regarding CPD content, pupils, and community to provide expert support and challenge via:

- Challenging of orthodoxies

- Illustration of practices from other settings

- $\quad$ Securing depth in learning via evaluation and design of CPDL activities

- Contextualization - ensuring content is contextualised for each subject but also for sub-groups of pupils-generic pedagogic CPD does not work on its own,

- Experimentation-effective CPDL involves carefully aligned sustained, iterative experimentation,

- Duration-iterative experimentation needs to be sustained over time to allow for gradual assimilation, testing and refinement. Short term CPDL can work for very tightly specified approaches to particular aspects of teaching for very specific stages in learning (e.g., spelling of a subgroup of words). Time is required to incorporate results into practice.

Selected Summary of Research on Key Elements of Effective CPDL Leadership

- $\quad$ Positioning CPDL as shared responsibility for pupil achievement and wellbeing

- Focusing on teachers' professional growth as well as developing knowledge/skills

- Modelling openness to professional/leadership learning

- Designing structures/systems for managing complexity taking fully into account the cognitive, practical \& emotional demands made by CPDL approaches and systems

Adapted from Cordingley et al. (2015, 2018, and 2020) [18-20].

What should be stressed in relation to pupil orientation, in particular, is that both providers and participants take the time and effort to be clear and specific about what the participants' pupils' learning will look like if the CPD is successful and to design and select activities on that basis. Also noteworthy is that one of the biggest practical challenges facing CPD providers is the huge range of starting points in relation to skills, knowledge, expertise and beliefs of the participating teachers, which inevitably makes differentiation demanding — and expensive (see Cordingley et al., 2018) [19].

\subsection{Effective Initial Teacher Education}

Effective initial teacher education to a large extent aligns with the above. But there are important differences and additional considerations to consider as Hargreaves (1993) [23] points out in his 'Practical Common-sense model of teacher development'. For example, pre-service teachers need rapidly to develop a body of knowledge and set of practical skills 
about the business of teaching and learning and to integrate the two within classroom contexts as well as with their specialist knowledge and skills. The literature and evidence base on effective ITE is limited; the following summary therefore is largely based on the experience of the review team and is primarily presented to surface our assumptions prior to the following review section. In overview, and in addition to the principles for effective continuing teacher education, we hold that ITE accentuates the following particular principles set out in Table 2, below:

Table 2. Overview of Additional Principles for Effective ITE.

\section{Summary of Principles for Effective ITE Additional to CPDL}

- Managing Overload-balance the need for explicit, detailed instruction and the need to meet statutory expectations with avoidance of overload, helping pre-service teachers focus on the fundamentals of practice.

- Foundational Curriculum-provide an especially coherent and well-sequenced curriculum that covers all foundational knowledge while meeting individual needs of pre-service teachers, allowing pre-service teachers to acquire and refresh a significant body of subject content knowledge (ck), pedagogical knowledge (pk) and pedagogical content knowledge (pck) in tandem, exploring how these come together and their relation to pupil needs and learning.

- Grounded Instruction - providing well-illustrated, contextualized instruction and the opportunities and skills to closely observe practice and develop as reflective practitioners.

- Manage risk and develop self-efficacy-helping pre-service teachers manage uncertainty and seek expert (including mentor) support, accessing the practical wisdom and reasoning of experienced teachers, and understanding how this relates to their own developing expertise (Twiselton, 2016), situating themselves in and contributing to supportive professional learning environments.

- $\quad$ Orientation to Professional Identity and Community — consider the implications of students typically being new to the world of work, professional working and school communities, supporting students to adopt a range of roles within a professional learning environment, begin the development of a holistic professional identity that fosters professional learning (of themselves and others), and advances and critically reflects on educational purposes and values of their communities and more widely.

- Organization of the curriculum to ensure content and aims are sequenced and prioritized to fit the training timescales, structure, statutory and non-statutory requirements of teacher preparation, and particular learning and practice settings.

There are several distinctions that are likely to have implications for the design of remote and blended approaches to ITE, relative to CPD for in-service teachers. Notably, ITE providers must manage the risk of knowledge overload-but also can build upon widespread recognition that there is a need to explore a large canvas. In contrast, for those supporting experienced teachers there exists an extensive iceberg of knowledge and skills that has can be deployed rapidly in classroom settings. Those supporting CPD need to find ways of helping teachers to surface, review and refine this knowledge base in the light of new approaches and evidence. ITE providers need to ensure they 'carefully craft coherently sequenced curricula that meet the particular needs of their trainee teachers, including the foundational knowledge of what subjects and curricula are', (DfE, 2019, p. 6) [24] Therefore, education and professional development for pre-service teachers needs to span a very wide 'curriculum' and providers can be relatively confident that pre-service teachers will not already have encountered many of the skills and much of the knowledge they need to acquire.

\section{Methods}

\subsection{Overview of Methods}

Scoping work, consisting of initial literature searches using major research databases (as used in the main review, see below), identified relevant reviews and background literature for inclusion in our descriptive and exploratory review sections (Sections 3 and 4, 
below). It also informed a review protocol containing a list of search databases, search terms, eligibility criteria and an overview of the evidence review process (Section 5) as described further below. In overview, our scoping work involved, first, initial location of key reviews of CPD and/or Teacher Education, its modality or both-sources were located through database searches and expert advice; second, developing a set of research questions that have been used to structure our main report (as above).

Given the time and budget constraints for this project, two review methods were blended to produce the most useful and highest-quality review:

- A Review of Reviews - to (a) identify findings pertaining to modality in existing reviews and (b) identify implications of CPD and ITE reviews for modality. Reviews were drawn on to develop the review conceptual framework, and to form the descriptive and exploratory discussion of relevant practice and theory underpinning Sections 3 and 4 . We also included background pieces identified during scoping, studies from within reviews, and studies within our evidence review database to develop these sections.

- A Rapid Evidence Review—systematically searching reviews and trials of distance and/or blended initial or continuing teacher education interventions. This includes studies of the relative effect of teacher education modality. In line with previous reviews of effective CPD (e.g., Cordingley et al., 2015) [18], we restricted our focus within the systematic element of the review to programmes reporting pupil outcomes (see below for further discussion of this point).

\subsection{Review of Review Methods}

When planning this review, the review team considered whether a rapid evidence assessment alone would be sufficient for informing practice in this area. We identified two main areas of methodological limitation of solely conducting a review of evidence from trials:

- First, the need to tightly focus search terms to identify studies with a specific modality focus, combined with the likely scenario that the literature is disparate and/or would provide only limited evidence, would result in lack of coverage of the rich combination of practices that comprise CPD; in other words, we were concerned that the review would be limited to discussing the small number of approaches which had been trialled and not be able to provide a broader account of remote and blended teacher education more generally.

- Second, we recognized that there were likely to be difficulties translating and applying the evidence to the specifics of the review and funder organizations' CPD offers and COVID-19 conditions. We felt that a more theoretical analysis would be needed to apply (a) teacher reviews (which are well-based in evidence) and (b) teacher education modality reviews which were unlikely to have a large, robust evidence base to draw on, to address our questions.

In short, we felt that a rapid evidence assessment alone would produce a report which would be too narrowly focused (on the limited causal evidence) and therefore would fail to provide a research-based account to many of the current questions which teacher educators had at the time. This motivated our 'review of reviews', or 'umbrella review' strand. A review of reviews, or 'umbrella review', synthesizes and revisits existing reviews in an area to identify key findings in the literature and give a high-level overview. Drawing on existing review work in an area increases efficiency, but reduces transparency, replicability and ability to define the focus of the review as it must work with the specific review questions used in extant studies. The 'umbrella' review focused on reviews or substantial reports (e.g., government or research organization) in two areas:

1. Reviews of teacher education (ITE or CPD) effectiveness

2. Reviews of blended and/or online teacher education.

This review had three objectives: 
- identifying additional remote and blended CPD trials within the studies included in the reviews for inclusion in the evidence assessment,

- identifying specific findings within the reviews pertaining specifically to CPD modality, - drawing out and discussing implications of general teacher education review findings for CPD modality.

This second strand of our review gives it more breadth and coverage than a rapid review can efficiently do alone and puts it in a position to build on and re-interpret existing work, drawing out implications for CPD modality. For the exploratory and discussion sections of the review (Sections 3 and 4, corresponding to research questions 1 and 2), we focused our attention on reviews in our database. We also drew on information from studies from the main evidence review (e.g., descriptions of remote and blended teacher education programs), pieces identified during scoping work, and pieces identified as potentially valuable to support background section during the searches (but not meeting the eligibility criteria for evidence review set out below). The groups of literature underpinning Sections 3 and 4 are listed below; we provide grouped reference lists for these in a supplementary document associated with this paper.

- Teacher Education, Professional Development and Learning Reviews-These were located during scoping searches and from pieces known to the review team. These are reviews of teacher education without a specific focus on remote or blended approaches.

- Remote or Blended Professional Development and Learning Reviews-These were located during scoping searches and from pieces known to the review team. These are reviews of teacher education with a specific focus on remote or blended approaches.

- Empirical Pieces-These are the main evidence review database of empirical tests of remote and blended approaches. These were located through systematic searches. Descriptions of approaches from within these informed descriptive and exploratory parts of this review.

- Background Pieces-These are neither reviews, nor trails, but retained during the search process as potentially providing descriptive or theoretical information supporting the initial review sections.

The key limitation of the exploratory review sections (Sections 3 and 4) is that, while systematic approaches were adopted, we relied heavily on our judgement and expertise in our selection of relevant literature and findings within it to summarize. This brings in an inevitable degree of subjectivity and reduces transparency. We have clearly cited all sources on which we have based our account and have not knowingly excluded relevant (including contradictory) results. We were guided by common principles of trustworthiness for qualitative analysis including: looking to triangulate empirical evidence and perspectives in the literature to gauge credibility; paying attention to and reporting details of the context of studies to assess transferability; underpinning our review with a systematic searching and screening process (see below, and Appendices A-C) and reporting of all relevant studies and findings to enhance confirmability; and detailed reporting of our methods here and in description of our process of enquiry in the substantive sections to encourage dependability in our results.

\subsection{Rapid Evidence Review Methods}

A rapid evidence review, or rapid evidence assessment, is a scaled down systematic review, in terms of time, budget and scope. It shares the need to use transparent and reproducible search techniques. It typically seeks to identify, screen and extract data from all relevant studies in a defined area (often focusing on causal evidence of impact from experimental or quasi-experimental work) but reduces the size of that area through narrower inclusion and exclusion criteria in terms of dates, focus and/or quality. The rapid review focused on the most relevant and robust studies that are available and be manageable within the constraints. It was unfeasible to review studies that do not have an explicit focus on CPD modality (i.e., by including all CPD trials and then identifying and assessing modality effects through data extraction and analysis). On the other hand, 
we recognized that the evidence base for CPD modality specifically was likely to be quite limited. As a result, we refined the focus and search terms for the rapid review following our scoping work to focus on the areas of the literature most likely to yield experimental or quasi-experimental results to inform practice. In overview, the rapid evidence review (Section 5) involved:

- Conducting exhaustive, systematic searching, screening and extraction for areas of the literature identified during scoping as most likely to yield experimental or quasiexperimental results to inform teacher CPD practice in remote and blended modes. Key search terms related to teachers (e.g., teach*), to professional development (e.g., educat*, train*, develop*), to modes (e.g., online, blended, remote, virtual etc.) and to methods (e.g., review, evaluation, trial etc.). Please see Appendix A for full details of the search terms, results and databases.

- Using research quality and relevance criteria to identify high quality papers for more detailed data extraction and analysis (see Appendices B and C). We extracted abstracts and key features (e.g., methods, findings) for all studies in the database. Due to the time constraints of the rapid review, we did not calculate inter-rater reliability for our screening process.

- Producing a narrative summary of the evidence. In the evidence review section (Section 5), we summarized all papers identified as eligible. For exploratory sections (Sections 3 and 4), we produced a selective narrative summary of papers that we judged to provide relevant findings against our pre-determined research questions and organizational structure.

The review eligibility criteria were as follows (see Appendix B for further details):

1. Date-Studies conducted in or after 2005 (searches were conducted in August 2020)

2. Learners-All children and young people form age 3-18 (inc. SEN and mainstream),

3. Teacher learning focus - Substantial focus on teacher learning,

4. Non-face-to-face element-All empirical and theoretical pieces that present findings about a mode of teacher learning other than face-to-face,

5. Pupil outcomes-All studies included in the evidence review must present some empirical evidence about the impact of the teacher learning on pupil outcomes.

This review obtained 7354 records from 5 search databases, containing dozens of library collections. We first screened these on titles for relevance and to remove duplicates, leaving 1716 records. We followed this with screening on our eligibility criteria (as above, and see Appendix B for further detail) using titles and abstracts (retaining 989 records) and then applying the same criteria to screening the full texts, retaining 73 documents. We retained a total of 19 background and wider pieces which, while they did not meet all eligibility criteria, were retained to provide background information and illustration of the results (see above). We also included several other pieces that were known to the team (see 'Other References', within the references list) and identified 4 'late entries' -3 reviews and one empirical piece (reporting early results of a program). We provide full search strings and the number of records located through each search in Appendix A. We provide an overview of the search process, with included and excluded records, by criterion in Appendix C. The key limitations of the evidence review were that (1) given the limited time scale, we did not calculate inter-rater reliability, (2) our search terms relied on the studies self-identifying as being blended, remote, online and other synonyms (rather than using general searches for teacher education and assessing mode ourselves), (3) the limited evidence base ( $n=24$ studies) and limited time led us to adopt a simple narrative review summary approach to synthesis; with more evidence and time it would have been possible to take a more granular, and systematic approach to extracting key details and findings of the studies.

In the Evidence Review section below (Section 5), only the 24 pieces fully meeting eligibility criteria are reported. In our wider discussion of approaches and their affordances (Sections 3-5, Q1, 2 and 4, as above), we draw on the full database, with a focus on the 
most up-to-date, relevant, and high-quality reviews. All papers to which we refer are cited throughout the piece. A full list of references by group is provided following the main body of this report.

\section{Remote and Blended Teacher Education Modes and Their Characteristics}

Question 1 (Q1). What forms of/approaches to remote or blended teacher education have been explored in the research literature? What are their typical characteristics/elements? How can this be organised?

Our first question relates to what approaches are evident in the literature and, presumably, also in common practice. Our aim here is to produce a functional framework, accompanied with some brief descriptions and illustration, to identify categories and key concepts that can be used throughout the review to support alignment and discussion of effective teacher learning principles with remote and blended teacher education approaches. We have not had the time nor resources to be systematic or comprehensive in this particular portion of the review, nor to step systematically through the empirical and review papers on which we have drawn. What we offer is a connoisseurial summary of what we found.

\subsection{A Working Framework of Remote and Blended Teacher Education Modes}

Based on our review database, we have developed the following simple framework of remote and blended teacher education modes. Whether these can accurately be described as modes, or whether we need to distinguish approaches, components, or media (for example) is not a question we pursue here. We simply note that, evident in our review database are numerous different approaches and characteristics of remote and blended teacher education approaches and variants and combinations thereof. Within these modes, there are clear links to be made in terms of overlap and modes that are typically combined (in particular the combination of modes 2 and 3, and of 4 and 5).

We identified six general modes of online or blended teacher education:

1. Lectures, workshops, seminars, discussion groups or conferences, including one-off sessions and series.

2. Coaching and mentoring.

3. Classroom observations with feedback and/or discussion.

4. Resource bases or repositories, with varying degrees of user interaction and content creation.

5. Platforms and self-study programs, ranging from less to more structured programs that give access to curated/designed resources, learning content, assessments and/or directed activities to learners.

6. Virtual reality spaces or simulations.

While these categories capture common types of activity, a large variation exists within and across these broad groups. We have also therefore identified several cross-cutting factors that characterize teacher education in the modes listed above.

Cross-cutting factors we found to characterise these modes are:

1. (A)synchronicity-With most of the above, it is possible to design asynchronous, synchronous and mixed variants. The advantages of each of these is discussed below.

2. Interactivity-Teacher education varies within and across programmes in the opportunities for interaction versus passivity, and the extent to which teachers are placed as consumers or producers.

3. Community-Programmes can be designed to be more or less collaborative, many seeking to form or situate activity within 'Professional Learning Communities' (PLCs). We note that other frameworks (e.g., Little and Housand, 2011, see below) [25] have PLCs as a mode in their own right. In our view, the extent to which teacher education is an individual affair or part of a community is a more cross-cutting question (i.e., PLCs operate across modes rather than being a mode per se). 
4. Choice of (Multi-)media-In remote and online teacher education program design, there is often a choice to be made between the use of video, audio and/or text as a medium of expression, for discussion or to convey information. Teacher education designers are now able to choose from several media and are typically opting for multimedia approaches. Moreover, as technology has improved, the inherent benefits of the media can be foregrounded in decisions, rather than the practicalities (e.g., cost and convenience) of the technology.

5. Combining Elements-Many programmes combine the overall modes, e.g., provide an online seminar followed by remote coaching. This is worth considering in relation to affordances below, that programme elements can be combined to ensure 'coverage' of teacher learning aims and principles and allow each medium and element to 'play to its strengths'.

6. Structure, design and facilitation-Programs vary in the extent to which they have been actively designed (as opposed to spontaneous and 'crowd-sourced') and the extent to which the activity is actively kept to this design through facilitation, direction (in person or through technology and activity timings and content). There are also more general organizational issues around the number, length and timing of programme inputs. While these may feel prosaic, as we discuss further below, these can have a significant impact on the impact of the teacher education and affordances around blended modes and activities.

7. Providers/Partnerships-One other consideration is about the provider(s). Many teacher education programs were delivered and/or designed by a combination of one or more teacher groups, schools, universities, and/or local/national authorities working in partnership.

8. Focus and purpose-A final key area of difference apparent in the literature is the extent to which teacher education in different modes is focused on/centred around a practical purpose (e.g., increasing STEM participation), by identity (secondary biology teachers discussion groups) or with a curricular/learning focus (learning and applying the principles of cognitive science).

We have created this two-part typology (modes-characteristics) both from and to structure this rapid review. We do not claim that it will necessarily map on to other and/or more wide-ranging sets of data/practice, nor do we claim that this is necessarily the most instructive way to conceptualize remote and blended teacher education so as to bring key teacher education or practical considerations into focus. One pertinent aspect that might be fruitful to examine in future is the availability of and resources for the technology involved. Resources, expertise and infrastructure for high-, medium- and low-tech approaches are likely to be key factors for applicability of this framework and the findings of this review across contexts. We also note that this typology is at a high level of granularity, with little detail on the underlying techniques and technologies (e.g., Bower, 2016 for a typology of specific Web 2.0 learning technologies) [26]. We compared our framework to other similar frameworks, with which it mostly aligns. Several examples of these are in Table 3, below: 
Table 3. Selected Typologies of Remote and blended Teacher Education from the Literature.

\begin{tabular}{|c|c|c|}
\hline $\begin{array}{l}\text { Little and Housand (2011) (as Quoted in } \\
\text { Elliot, 2017, pp. 120-121) }[25,27]\end{array}$ & Snell et al. (2019) p. 210 [28] & $\begin{array}{c}\text { Horn and Staker, } 2011 \\
\text { (as Quoted in Burns, 2011, p. 70) [10,29] }\end{array}$ \\
\hline $\begin{array}{l}\text { Mode 1-The first mode of online } \\
\text { professional development is accessible } \\
\text { websites or online resources. } \\
\text { Mode 2-The second mode of online } \\
\text { professional development is technology } \\
\text { for face-to-face interaction with } \\
\text { audiences in real time. } \\
\text { Mode 3-The third mode of online } \\
\text { professional development is professional } \\
\text { development supported by asynchronous } \\
\text { online discussion. } \\
\text { Mode } 4 \text {-The fourth mode of online } \\
\text { professional development delivery is } \\
\text { videoconferencing. } \\
\text { Mode 5-The fifth mode of professional } \\
\text { development is constructing and } \\
\text { facilitating an ongoing online community. }\end{array}$ & $\begin{array}{l}\text { (1) Remote, non-live, asynchronous } \\
\text { coaching consists of coaches who work } \\
\text { with teachers remotely, including via } \\
\text { video sent by teachers to coaches, and } \\
\text { phone or e-mail exchanges between } \\
\text { coach and teacher about the content. } \\
\text { (2) Remote live coaching consists of } \\
\text { coaches observing and providing } \\
\text { feedback to teachers live, using webcams. } \\
\text { (3) Online course content allows teachers } \\
\text { to access online materials and read about } \\
\text { [curriculum content], watch videos, and } \\
\text { take quizzes. } \\
\text { (4) Online group courses or satellite } \\
\text { courses are similar to standard PD, except } \\
\text { that teachers attend a viewing of the PD } \\
\text { programme offered online or over } \\
\text { satellite with other groups of teachers. } \\
\text { (5) Online downloadable curriculum or } \\
\text { lesson plans consist of resources available } \\
\text { online for teachers to use in the } \\
\text { classroom. }\end{array}$ & $\begin{array}{l}\text { 1. Face-to-Face Driver Model: The } \\
\text { face-to-face teacher delivers most of the } \\
\text { curriculum and uses online materials to } \\
\text { supplement. This model often occurs in a } \\
\text { computer lab. } \\
\text { 2. Rotation Model: Students rotate } \\
\text { equally between face-to-face and online } \\
\text { components of the course on a fixed } \\
\text { schedule. They have the same teacher for } \\
\text { each component. The online component } \\
\text { occurs remotely. } \\
\text { 3. Flex Model: The online component } \\
\text { delivers most of the information, with an } \\
\text { in-class teacher present to provide } \\
\text { flexible support as needed. This model } \\
\text { includes lots of individual and } \\
\text { small-group, face-to-face tutoring. } \\
\text { 4. Online Lab Model: The online teacher } \\
\text { delivers the course in a brick-and-mortar } \\
\text { classroom, but with paraprofessional or } \\
\text { teacher aides supervising students. } \\
\text { 5. Self-blend Model: Individual students } \\
\text { take online courses à la carte. Online } \\
\text { learning is remote, but traditional } \\
\text { instruction is brick-and-mortar. } \\
\text { 6. Online Platform Model: Instruction } \\
\text { and materials are all online, with } \\
\text { students taking the course remotely. } \\
\text { Weekly check-ins with a face-to-face } \\
\text { supervisor or teacher are required. }\end{array}$ \\
\hline
\end{tabular}

\subsection{Selected Examples and Illustrations}

In this section we discuss and provide selected illustrative examples of remote and blended teacher education approaches, in line with our framework and drawing on the literature we have reviewed. For online initial teacher education, Dyment and Downing (2020) [11] provide an up-to-date and systematic mapping of the literature. This literature is replete with varied examples of practices in online ITE; indeed, as the review authors find in their first theme in the literature, over three quarters $(n=381)$ of the 492 papers they reviewed profiled an online pedagogical 'innovation'. These included, 'a wide diversity of synchronous and asynchronous innovations ... web conferences, discussion boards, chat rooms, instant messaging, digital games, social media, virtual laboratories, virtual simulators, discussion boards, portfolios, and Facebook" (Dyment and Downing, 2020, p. 326) [11]. The papers often described the use of these innovations in ITE courses, as well as the affordances they could offer teacher educators and ITE students. As per their third theme, a small number $(14 \%)$ of articles profiled how the approach had been contextualized in specific subjects or curriculum areas. The focus of most of these papers was more whether it was 'possible' for these areas to be taught online, rather than the technological innovations per se, and identifying the strengths and weaknesses of the online mode as experienced by both ITE students and teacher educators (ibid. p. 327).

Having located this systematic review, our aim is not to unpack these studies to the point of providing further elaboration on the details of innovations and practices. Instead, we refer the reader to the Dyment and Downing (2020) [11] review and the papers therein. In the remainder of this section, we describe each of our modes. We have identified several reviews and case studies that allow us to give an overview and illustrative examples. We 
note that we are not advancing any of these as examples of effective teacher education, rather they are just examples of programs that fall within our typology and allow us to explore characteristics, variations and issues of the modes before the next section where we consider remote and blended teacher education and the principles for effective teacher education side-by-side.

\subsubsection{Mode 1-Lectures, Workshops, Seminars, Discussion Groups or Conferences}

Our first mode for blended and remote teacher education consists of approaches that facilitate dialogue between a teacher or pre-service teachers and other teachers, preservice teachers, instructors, experts, stakeholders, or a combination of these. However, at the boundaries of this are: firstly, lectures, which can often include minimal dialogue and are therefore more akin to video content on platforms and self-study programs (see mode 5); second, conferences, which typically combine numerous elements of which only some resemble a seminar or discussion group. When it comes to conference keynotes and presentations, where the information flow is one directional, these may be thought of as being more similar to static content and our content platform mode (5); when it comes to unstructured discussion between conference delegates, this can have the qualities of more informal professional learning communities (a cross cutting characteristic discussed below); for conference question and answer or discussion-focused sessions/periods, we feel these have a great deal in common with seminars and workshops, sharing the characteristic of facilitated discussion that we have identified for this mode.

Varying interactivity and structure within conferences is one theme discussed in Seddon et al. (2012) [30], who present a model of web conference activity over the course of the conference in terms of their level of social interaction, information provision, internalization of information by participants and co-construction of knowledge. They find, in short, that: 'Social interaction was most noticeable at the beginning of sessions then tailed off as the presentations started, but reappeared at the end, as networking for the future occurred' (p. 445). The more general point, applying across all modes, is that the amount of discussion, and information presentation is variable both across and within modes, but even within individual units or sessions in a specific approach. As we touch on above, as technology has improved, teacher education providers are increasingly able to choose the medium/media of expression according to what is effective and desirable rather than what is practicable. For example, and of particular note, is that in recent years it has become increasingly possible to enhance teacher education through interactive use of video to support observation, discussion, modelling, mentoring and coaching. Recent developments in technology have enabled synchronous, video-based small group activity within larger group workshops. This is an important new affordance that has been widely used during COVID-19 lock-down, for example, to enrich peer support and differentiation but is unlikely, as yet to feature in the research. There are, however, numerous examples in the research of the use of video for remote seminar/workshop or conference discussion.

One extended discussion of this practice in connection with video conferencing is found in Burns (2011) [10]. Burns (2011) [10] particularly noted that the medium gave access to learning experiences that geographically distant teachers might not otherwise be able to participate in, while also reducing misunderstandings caused by the lack of nonverbal cues that may characterize other forms of online learning. However, there remain issues such as audio-visual quality, time lags, drops in service, coordination of activities and suitability of activities for the medium (Burns, 2011) [10]. We note the date (2011, discussing a Canadian network operating in 2001-2002) and the discussion of technological as well as teaching and learning considerations. Finally, Burns (2011) [10] noted that the instructor may not be able to see all the participants and that working with simultaneous face-to-face and remote groups might mean that one group was prioritized over the other.

Another key consideration for lectures, workshops, seminars, discussion groups and conferences is whether these are one-off events, part of a series and/or linked to other forms of activity. The hallmark of activity within this mode is to structure discussion 
around focus questions or content. Decisions around the number of sessions, their duration and timings shape how long the 'conversation' can continue, and the depth and quality in which the questions/content can be considered. Choices around frequency and timings also affect who can participate and the extent to which other teacher education activities can take place between the sessions. A seminar series spread across a school term, for example, allows classroom and other teacher education activity to occur alongside the series and links to be made between these. A conference-even if the questions, content, and opportunities for discussion remain the same-is harder to integrate with other activity in this way.

\subsubsection{Mode 2-Coaching and Mentoring}

Relative to other modes discussed here, coaching and mentoring are relatively welldefined (and have a strong evidence base finding substantial impacts on teacher learning and pupil outcomes (e.g., see Kraft, Blazar and Hogan, 2018) [31], although practice and quality varies considerably (Hill et al., 2020) [5]. The National Framework for Mentoring and Coaching (CUREE, 2005) [32] describes and explains the principles, concepts and skills for mentoring and coaching and compares the overlaps between these (also see Cordingley, and Buckler 2012, and Fletcher and Mullen, 2012) [33,34]. The main difference between remote coaching and mentoring and face-to-face variants is simply that remote versions of coaching and mentoring must use video, audio or textual media to facilitate exchange between the coach/mentor and coachee/mentee. The media ostensibly vary in their suitability and affordances to sustain high quality mentoring and coaching conversations and to the degree they enable synchronous and asynchronous conversations.

\subsubsection{Mode 3-Classroom Observations with Feedback and/or Discussion}

Closely linked to mentoring and coaching is the observation of classroom teaching. We have included this as a separate mode as video technology allows discussion of classroom teaching in other forms of teacher education, including in discussion groups or on online repositories. So much so that one might argue that rather than being a mode in their own right, classroom observations with discussion and feedback are simply the content for other forms of interaction. Be this as it may, given the centrality of observation of classroom practice to many forms of teacher education and the growing possibilities for (synchronous and asynchronous) observation of classroom teaching afforded by developments in video technology and platforms, we have categorized classroom observation as a mode in its own right.

The literature on the use of classroom video for professional learning is summarized and discussed in Perry et al. (2020) [35]; a short summary of selected points from this is provided below, along with an example. Perry et al. provide an overview of potential affordances of video observations for enabling and enhancing CPD, based on reviews in the literature (e.g., Brouwer, 2011; Gaudin \& Chaliès, 2015; Major \& Watson, 2018) [36-38]:

- It captures classroom interactions for review outside of the classroom (Brouwer, Besselink, \& Oosterheert, 2017; Pehmer, Gröschner, \& Seidel, 2015; Tripp \& Rich, 2012) [39-41].

- It can foster collaborative approaches to professional development: making it possible for joint learning between colleagues and/or external experts (Brouwer et al., 2017) [39].

- It may assist teachers to recognize previously unnoticed issues, allowing conceptions to change (Gaudin \& Chaliès, 2015) [37]; a feature recognised by the 'Lesson Study' (e.g., Lewis, Perry, \& Murata, 2006) [42] and 'Learning Study' (Davies \& Dunnill, 2008; Holmqvist, 2010) [43,44] literature.

- It can offer convenient opportunities outside the school day for observations and discussions with teachers and their colleagues, reducing supply cover costs (Quinn et al., 2019) [16]. 
- It is efficient, in that the most instructive videos can be viewed repeatedly by a wider audience.

- The use of video platforms can support processes of teacher reflection, discussion and analysis through tools for editing or annotation (Rich \& Hannafin, 2009) [45].

Running through these points one can see the connection with: external expertise and perspectives; discussion groups; enquiry and action research approaches; and platformshence why this may be thought of as an activity within more than a mode of teacher education. Questions that arise from this literature include whether it is of greater impact to review one's own teaching, or that of others (including colleagues or experts). When this was systematically studied the answer seemed to be 'both': viewing of the work of others can make teachers more receptive to new ideas and more engaged in the analysis of difficult incidents (e.g., Van Es, 2012; Borko et al. 2008; Kleinknecht and Schneider, 2013) [46-48], but this appears to be especially effective when viewing videos of others is preceded by teachers reviewing their own teaching (e.g., Beisiegel et al., 2017; Seidel, Stürmer, Blomberg, Kobarg, \& Schwindt, 2011) [49,50]—it seems it is the connection that counts.

One example in this area is Jamil and Hamre (2018) [51] in their study of online professional development on principles of learning from cognitive science. The programme takes a structured approach to teacher reflection asking teachers to observe, analyze, assess and plan, which the authors discuss in relation to cognitive science principles. In relation to observation, they draw attention to the value of videos for identifying specific, situated interactions and opening these up for conscious consideration, examining what are often tacit and unconscious decisions based on automatic schema, making them explicit again (p. 228). They find that the approach can enable teachers to examine objectively the consequences of their actions by distancing them from the immediate, emotional reactions to the situations (Jamil \& Hamre, 2018) [51].

In overview, videos of classroom teaching provide teachers with 'objects to think with' (Jamil \& Hamre, 2018, p. 74) [51], which connect in a concrete and authentic way to teacher's practice. Use of classroom videos is widely held to hold promise for effective professional learning. The evidence base, however, is not yet sufficiently developed to either support or refute this perception.

\subsubsection{Mode 4-Resource Bases or Repositories}

Another mode that has not sat easily as a stand-alone item in our typology is that of resource bases or repositories. Should providing access to a resource base even qualify in its own right as a form of teacher education? We are left wondering whether resources bases are better thought of as being content or curricula for teacher education rather than types of it, though we observe that many view curriculum materials as 'an important source of teacher professional learning in and of themselves' (Hill et al., 2020, p. 52) [5]. This question aside, there are numerous examples of resources bases that - to varying degreesencourage teacher collaboration and professional learning through creation, discussion and use of resources ranging from lesson plans and curriculum schemes of work to worksheets, ideas, stimulus material and assessment tools for use in the classroom.

The Times Educational Supplement (TES) teaching resources page provides over 900,000 resources made by teachers, sorted into curriculum areas and topics, with the option to review resources and join in with over 250,000 discussion threads in the community section. More recent examples include Teacherly, which emphasizes to a greater extent the collaborative and professional learning aspects of resource creation and sharing, as well as providing a platform for remote teaching. Similarly, linking with the previous section, is that there are examples of resource bases that include classroom videos, such as those investigated in Bates, Phalen and Moran (2016) [52], which at the time they were writing housed over 350 video clips used by over 37,000 members. As noted by Dede et al. (2016) [53], resource collections can also include tools and apps; also, as groups get large, 'crowd sourcing' even specialist, topic or subject-specific resources becomes more 
viable. Members of the review team are increasingly seeing schools and groups of school developing their own approaches to collaboration and sharing of resources (such as using software such as SharePoint, Google Drive and other similar platforms). Before moving on, we note the parallels here with the questions that arise in relation to PLCs (below) relating to quality control, depth of engagement and participation.

\subsubsection{Mode 5-Platforms and Self-Study Programmes}

Many programs we have reviewed are based around an online platform, or virtual learning environment. This is the area that is most varied in terms of content, activities (and apparently quality) and there are many points of contact with other modes. Indeed, it is possible to describe most online platforms for teacher education as being a curated, structured resource base (often with added instructional material) with wrap-around collaboration and expert input in the form of seminars, mentoring, discussion groups and or (less commonly) lesson observations. Moreover, where a platform and its associated activities bring together teachers and pre-service teachers for discussion, sharing and support, it can be said to be an organizational focal point for a PLC. In short, teacher education online platforms and programs that use them can and often do incorporate one or more (other) modes of teacher education. Typical examples include Dana et al. (2017) [54], who provide a detailed description of the Prime Online program, a year-long program designed to develop subject (pedagogical) content knowledge and pedagogical content knowledge in mathematics elementary (primary) classrooms through practitioner inquiry. The Prime Online experience consisted of "three distinct, yet integrated, segments of weekly modules consisting of content and experiences designed to build on one another" (Dana et al., 2017, p. 215) [54]. It was designed and delivered via Moodle ${ }^{\mathrm{TM}}$ (an online learning platform), with a consistent, four-component format for each module.

The learners begin each week by logging in to find an introduction and an overview of activities for that week, including aims and resources (Dana et al., 2017) [54]. They have an Anticipatory Activity that consists of some sort of provocation to enable them to reflect on prior experiences and connect them to the new material plus readings, videos and 'web quests' (ibid p. 215). The learning is assessed through assignments where participants have to apply what has been learned to their classroom practice and whole group learning and discussion is summarized and analyzed by the facilitator (ibid). Dana et al. (2017) [54] go on to discuss the program, its content and how participants engaged with it in detail. While their focus is more on practitioner inquiry than the affordances of online teacher learning approaches, it nonetheless provides a rich illustration of how online approaches to teacher learning can be designed and implemented. Although space does not permit us to pursue them further here, other rich examples of programs in this area are provided in Owston et al. (2008) [55], who review three program evaluations of blended teacher professional development and exploring, for example, issues around program structure and its links to expectations and relevance. As Owston et al. (2008, p. 208) [55] describe, "the more structure that a program imposed, the less flexibility it provided teachers to experiment with activities in the classroom at same time they were planning on teaching them".

In sum, learning platforms are clearly performing multiple functions, bringing together and organizing teacher education modes, content and activities. 71 out of 89 studies of professional development programs for STEM teachers reviewed by Hill et al. (2020) [5] for example combined new curriculum materials for teachers to use in classrooms with professional development. Elliot (2017, p. 121) [27], in their review, discuss how 'course management systems' or 'learning management systems', which they define as a 'collection of online learning tools contained in one system' can be used to achieve multiple aims, also cautioning against the assumption that conventional face-to-face programs can be straight-forwardly transferred into the differing dynamics of online environments. 


\subsubsection{Mode 6-Virtual Reality Spaces or Simulations}

The final mode that we have identified but will not be pursing further past this brief section is the use of virtual reality (VR) or simulation spaces for teacher education. This includes the use of virtual environments such as the popular 'Second Life' virtual world as a space for developing teaching skills or its components and the use of VR to immerse teachers in observation of virtual reality classrooms (i.e., 360-degree videos of real classroom activity). Burns (2011) [10] describes the "immersive, highly synchronous attributes" (p. 100) of one popular virtual reality space, Second Life, as having huge potential as a distance learning tool. We refer readers interested in finding out more about virtual worlds to systematic reviews by Theelen, Van den Beemt and den Brok (2019) [56] — focused on interpersonal competence for pre-service teachers-and Billingsley et al. (2019) [57], who systematically examine VR in pre-service and in-service programs.

When it comes to VR classroom experiences, we feel that many of the affordances and questions linked to the use of classroom video, as discussed above, apply. Like classroom video, VR technology promises the potential for immersive and concrete classroom experience, which when organized around principles for effective teacher education apparently have great potential to support teacher learning.

\subsection{Professional Learning Communities}

Before moving on to discuss the affordances and limitations of remote and blended modes, we consider one of the cross-cutting factors in our framework: the extent to which the teacher education program is delivered within and/or forms a professional learning community (as opposed to individual-level, or small group teacher education). While other cross-cutting factors are discussed in specific sections throughout the report, as PLCs are in other reviews considered a mode and, moreover, raise many common issues around the nature of collaboration, expertise and focus, this area warranted a dedicated section.

Remote and blended professional learning communities have attracted considerable attention from both practitioners and researchers. It is an area of this literature that comprises not only numerous research pieces, including many case studies, but a growing body of meta-analyses, reviews and reports. This is a sign of the growing maturity of both research and practice in this area. This said, what is not yet evident in the literature (or at least from our searches) are many examples of attempts to evaluate the impact of online (or indeed any) professional learning communities in terms of their impact on pupils, as opposed to changes in teacher practices or teacher satisfaction. PLCs have evolved for numerous purposes and have not always been well aligned to principles for effective teacher education. While we can provide-via reviews identified in the study-a descriptive and theoretical account, some caution is needed in drawing any conclusions about the design principles for effective teacher education within PLCs.

We identified numerous case studies and reviews focused on online or blended professional learning communities. There was huge variety evident, something that the reviews in the area have also grappled with (e.g., Macià and García, 2016; Lantz-Andersson, Lundin and Selwyn, 2018; Khalid and Strange, 2016) [58-60]. Macià \& García (2016) [58] found that the range of online communities and networks for teacher PD is wide and still in fairly early development, the corresponding theoretical frameworks are quite varied and hard to compare, and that the practical impact on teacher PD is unproven and the mechanics of such impact unclear. Remote and blended professional learning communities vary in terms of (for example):

- Formal or informal organization (Lantz-Andersson et al., 2018) [59].

- Extent of time commitment desired and achieved by individuals and the combined community.

- The media/technologies employed for PLC activities and discussion. However, much of the research in this area fails to mention or describe the technological basis for the PLC in any detail (Lantz-Andersson et al., 2018, p. 305) [59]. Technology, particularly 
in relation to issues of access and technological understanding of potential PLC members, is perceived as a key barrier to participation (Khalid and Strange, 2016) [60].

- Their focus and activities (see below).

- Their size and geographical reach.

- The heterogeneity of the community in terms of their phase, subject expertise and so on.

- The balance of online to face-to-face contact for blended communities.

This list, while far from exhaustive, already casts PLCs as a fairly nebulous concept. What seems to be common to PLCs is that they bring groups of educators together around a purpose (e.g., a school improvement initiative) and/or identity (e.g., secondary biology teachers interested in research-informed practice). It is this that motivates our decision to classify PLCs as a factor rather than a mode. PLCs could therefore be a group that meets to observe and discuss teaching (mode 1 ) or one based around a teacher education programme using a virtual learning platform (mode 5), and so on. PLCs frequently extend other teacher activity, creating additional opportunity for collaboration, discussion and sharing. They also exist in their own right, again varied, and characterized in part by the above factors. PLCs existing in their own right often centre on sharing and peer support. In their systematic review of formal and informal PLCs, Lantz-Andersson et al. (2018) [59] describe the sharing function of PLCs as distinct from the construct of professional learning as focusing on a narrow syllabus because it can distil information from the knowledge and experiences of the group. Nevertheless, they do caution that PLCs may not lead to deeper level learning as many often became " ... sites for 'superficial' sharing of information, quick exchanges and a 'smash-and-grab' approach to becoming informed" (Lantz-Andersson et al., 2018, p. 311) [59].

Capturing some of the possible benefits of PLCs, as discussed above, Frumin et al. describe the nature, organization and timings of activity in an Advanced Placement Teacher Community (APTC). The online community is generally sustained by the activity of the teachers themselves, though each APTC does have a moderator. In contrast to other PD offers, the APTC can be accessed flexibly throughout the year and around the clock. They add: "In addition to being 'bottom-up' and ongoing, the APTC has the following two primary attributes, based on survey and case study data, that complement and extend topdown forms of professional development: (1) personalisation of content and (2) a shared, affective community" (Frumin et al., 2018, p. 413) [61].

Despite (or perhaps because) of their bottom-up and ongoing nature, PLCs can have issues with engagement levels from all members of the community. Frumin et al. (2018) [61] found that only about half of their survey respondents used the APTC and many of the participants in the online community were what is known as 'lurkers' (i.e., individuals who observe but do not actively participate-something we discuss further below). They also find (and this is echoed in Khalid and Strange, 2016) [60] that PLC members can struggle to feel safe (e.g., from criticism or judgement) or able (e.g., technological, cultural or expert knowledge) to fully participate in the community. Some survey respondents in Frumin et al. (2018, p. 415) [61] 'note that the online community does not always feel safe given the employed moderation techniques (or lack thereof) and/or the domination (or bullying) by a few strong voices.' Other rich case studies we have examined in our review include Holmes (2013) [62], who presents a case study of eTwinning professional learning community, and Dede et al. (2016, Chapter 6) [53], who describe a 'Just-in-time' professional development community called the 'Active Physics Teacher Community' that "has the specific intention of helping teachers plan their daily lessons and 'providing them with formal instruction that is directly related to the lessons they are teaching; share their knowledge, experiences, successes, and challenges with other teachers who are using the same lesson plans and curriculum; and compare the effectiveness of their teaching ..." (Dede et al., 2016, p. 162, Chapter 6) [53]. 


\section{Affordances and Limitations of Remote and Blended Approaches to Teacher Education}

Question $2(\mathbf{Q} 2)$. What are the affordances and limitations of remote and blended teacher education relative to face-to-face variants? What adaptations, restrictions or enhancements are typical relative to face-to-face variants?

We tackle this question from two perspectives:

a. What, from a theoretical standpoint, can be inferred from the literature on effective continuing professional development and learning (CPDL) and initial teacher education (ITE)?

b. What is advocated as best practice in the remote/blended teacher education literature?

It should be stressed that this is an exploratory treatment of the question. While reviews such as Surrette and Johnson (2015) [63] and several other pieces we discuss below provided an excellent starting point, the literature (even when taken as a whole) did not yield an extended or comprehensive account. So, in what follows we draw on our own expertise as well as the studies and reviews in the review database, where these discuss or present relevant principles and issues. This is an exercise in synthesis and interpretation that is not (unlike our evidence review) based on exhaustive and systematic treatment of relevant studies. Our aim is to entertain and explore hypotheses and plausible connections between the effective teacher education principles and the affordances, limitations and practice of remote and blended teacher education.

Our opening observation is that remote and blended teacher education is a broad church. The accounts of many of our review studies tell us something about a program, but not about the modality in general. As discussed above, there is huge variation in practice and the technologies employed with each mode, and the apparent quality in their implementation. Reflecting this, and also our response to it, is a comment from Dede et al. (2016) [53] in relation to technology:

"When compared to context, goals, or pedagogical design, technology is arguably the least important component of a learning environment. That being said, the affordances of different technologies enable new variations and forms of organizing activity. There are activities which are much easier to do with particular technologies when they are used well."

(Dede et al., 2016, p. 36) [53]

Therefore, we think there is currently great value in reviewing modes and technologies of teacher education in relation to and while not losing sight of teacher education principles, not least because of the possibilities and potential for missteps of the rapidly developing potential for remote and blended teacher education being opened up by technological development and circumstance (including the present COVID-19 pandemic). The reviews we have examined reveal a landscape which is 'a divided, unsettled, and challenging space with pockets of acceptance, but characterized by epistemological and pedagogical questions, doubts, and uneasiness' (Dyment and Downing, 2020, p. 327, commenting on online/blended ITE but in our view more widely applicable) [11].

While one modality may not be necessarily superior to others and the implementation is as important as the design, the affordances and limitations of the modes do seem to vary. Indeed, the fact that many programs are combining modes and approaches is often in deliberate recognition of the strengths and weaknesses of each (Elliot, 2017) [27]. There is, therefore, value in attempting to grasp these. We continue this discussion in connection with specific teacher education principles and perspectives presented in the review introduction (Sections 1.2 and 1.3). To ease this discussion, the principles have been grouped with each other and related CPDL, leadership of CPDL and ITE principles connected where possible. While there is obviously no perfect grouping and delineation possible, these do bring together some connected considerations pertaining to teacher 
education modality for pre-service teachers, teachers and leaders for a more focused discussion.

\subsection{Pupil Orientation}

Perhaps surprisingly, there is very little focus on pupil outcomes in the teacher education online/blended literature, much of which is focused on changes in teacher practices or thinking and/or teacher perceptions on and experiences of new ways of learning; this is especially true for the initial teacher education literature (Dyment and Downing, 2020) [11]. This can also be seen in our searches: when we screened 989 papers using full-texts 749 (over $75 \%$ ) were excluded from the review as they reported no empirical data on pupil outcomes arising from the teacher education of any kind. This runs counter to the finding in the effective teacher education literature (e.g., see Cordingley et al., 2015) [18] that the organization of CPDL around teachers' aspirations for pupils and how teaching practices affect learners and learning was the only common feature of all effective CPDL. It is therefore a concern that such a large proportion of pieces describing and evaluating teacher education programs paid such little attention to what, if any, benefits and impacts there were for pupils.

For an example of a programme where a pupil orientation was evident, we can return to the previously discussed 'Just-in-time' Advanced Placement Teacher Community (APTC) reported in Dede et al. (2016, Chapter 6) [53]. The programme platform was structured around a 'Prepare, Share, Compare' pattern, linked to the 'Active Physics' curriculum and its associated textbook and typical teaching structure. On the prepare portion of the platform (see p. 162 for further details) teachers could access videos, lesson plans and were provided with information on the science content and common misconceptions etc.; Share was designed to allow teachers to share experiences, ask questions and receive responses from other members of the community in relation to content, pedagogy (and pedagogical content knowledge); on the Compare section, and pertinent here, is the space and expectation for teachers to use pupil data from quizzes to discuss their impact on pupils and inform their future instruction. The detailed discussion of the Compare feature is particularly relevant to this section. This feature allows the participants to examine the progress and scores of their own students with those of other teachers, as well as explore why the differences may have arisen, why students may have been drawn to incorrect answers, and use the data to improve their practice. These characteristics are unique to his forum and are not replicable in classic forms of PD as there is usually a delay between the classroom activities and the analysis (Levy, Eisenkraft and Fields, in Dede et al., 2016) [53]. It is noted that this collaborative approach was adapted from the Japanese practice of Lesson Study, but the online format enables wider engagement in a "real-time, just-in-time context" (Levy, Eisenkraft and Fields, in Dede et al., 2016, p. 174-175) [53]. We are also reminded of the previously mentioned discussion of video observation in relation to cognitive science principles in (Jamil and Hamre, 2018) [51], who describe the analysis of classroom observations to 'make an honest appraisal of the consequences of these interactions for [the] students' (Jamil and Hamre, 2018, p. 229) [51].

A pupil orientation goes beyond including some consideration of pupil outcomes (e.g., via for example analysis of pupil work or assessments during initial planning or following a lesson observation). Having a pupil orientation is to use aspirations for pupil experience and outcomes as a way of focusing and making coherent, all aspects of the teacher education activities, whether one is designing a curriculum, developing questioning technique or learning about effective assessment. 'How will children/young people benefit from, react to, and/or experience this?' and, 'How have children/young people benefited from, reacted to, and/or experienced this?' are the central, yet often neglected, questions at the heart of all teacher education activity.

We now turn to the general question of which teacher education modes are a good 'fit' for achieving this feature of teacher education. The general principle of 'distance to practice' highlights that technology (and especially video) has the potential to bring classroom 
interactions into a teacher education space for examination, discussion and reflection, without the expense of face-to-face observations (i.e., around release time) and the reliance on memory-which will be most fresh immediately after the teaching and increasingly distant as time passes. We note that in Levy et al. [53], 'student results and memory of what transpired in classes' is the basis for discussion and practice development, whereas Jamil and Hamre discuss 'precise' and 'specific' interactions and their consequences. Remote and blended modes provide - to a greater or lesser extent-a multimedia space to which it is possible to bring rich practice and pupil outcome stimuli for detailed discussion; some of these (e.g., planned seminars and platforms) tend to allow more structure (which allows pupil orientation to be 'built-in'); whereas for others (and especially informal online professional learning communities), it may be difficult to ensure a pupil orientation.

Overall, we judge that there are no modes within our framework for which it is not possible to include substantial consideration of pupil outcomes, and many which have advantages (such as cost and ability to create a larger community) when compared to faceto-face methods. Discussion of pupil outcomes is made easier when student assessments or artefacts (e.g., pupil work) as stimulus material and classroom video are built into the teacher education to make links between teaching and learning.

\subsection{Collaboration and Support}

A common characteristic of teacher education is collaboration. Being supportive of collaboration is one the elements of effective professional development identified in Darling-Hammond et al. (2017) [21], who explain that:

"High-quality PD creates space for teachers to share ideas and collaborate in their learning, often in job-embedded contexts. By working collaboratively, teachers can create communities that positively change the culture and instruction of their entire grade level, department, school and/or district."

(Darling-Hammond et al., 2017, p.v.) [21]

With this principle and others, it is important not to take the simplistic interpretation that its mere presence will make for effective CPDL, or indeed that it is either a necessary or sufficient condition for effective CPDL. A pupil orientation (see previous) provides the most concrete example of another factor that may or may not be evident within collaborative activity. That is, collaboration can be a superficial 'sharing of best practice' or a rich exchange orientated towards how pupils are responding to teaching practices and curriculum, examining theory and practice side-by-side through iterative classroom 'experiments', and that is sensitive to participants' level of experience (cf. the other teacher education principles). It is not the presence of collaboration per se that matters; it is the who, what, where, why and how of it, and how it aligns to the other effective teacher education principles (and especially pupil orientation) which requires consideration.

Putting the detail of what constitutes effective teacher education aside, the focus here is on the 'fit' of particular principles with remote and blended modes of teacher education, and what new affordances, limitations and considerations come to light when putting teacher education principles and what we know about remote and blended teacher education modes side by side.

\subsubsection{Presence, Participation and Facilitation}

A concept that appears often in the literature we have reviewed is that of 'presence', its importance and the potential difficulties of achieving it remotely. Elliott (2017, p. 118) [27] argues that PLCs ('Communities of Inquiry' in their terms) provide a model for effective practice across any online learning experience which includes 'social presence'. Eliot also discusses 'cognitive presence', and 'teaching presence' (p. 118), which refer respectively to how learners interact with the content in the environment, and the instructional design and delivery within the course. Surrette and Johnson's 2015 [63] meta-analysis suggests that it is possible to achieve all of these within an online space. Their analysis of 20 empirical studies (ranging from single-case qualitative studies to randomised controlled trials) 
indicated that 'online PD that facilitated opportunities for collective participation enabled the teachers to (a) experience a high level of social connection with their peers, (b) engage in multiple opportunities to reflect on their teacher practice and the practice of their peers, (c) share knowledge and experiences with peers, and (d) increase their knowledge and understanding of unique instructional strategies' (Surrette and Johnson, 2015, p. 266) [63]. Similarly, there are examples (e.g., Lin, 2008, in Keengwe and Kang, 2013, p. 487) [64,65] of students feeling a sense of 'connection and active participation through online discussion' even within a text-only format of an online discussion board. In some cases, interactions being online and/or asynchronous even has advantages for participation, including less confident students being 'able to take the time to compose a response' and participation being less tied to geography and timings of face-to-face interactions.

While high 'presence' appears to be possible, it also seems to need careful consideration when designing remote and blended teacher education. High participant attrition seems to be a general issue for online modes of delivery (e.g., see Goldenberg et al., 2014) [66] as well as the issue of non- or highly-passive participation (Keengwe and Kang, 2013) [64], with interactions being overly tutor-initiated and student responses limited in number or depth (Lantz-Andersson et al., 2018, p. 309) [59]. The inherent limitation of all non-face-to-face interaction, as Quinn et al. (2019, p. 410) [16] explain, is that 'in online settings, the capacity to read body language and facial expression is limited, especially if communication is primarily through text, which challenges the intimacy and immediacy required for social presence ( $\mathrm{Tu}$ and McIsaac 2002)' [67]. This sense of connection with present, responsive others is not always achieved, as the teacher quotation in Owston et al. (2008) [55] vividly captures:

"The one thing I found about [the online discussions] was that I get all these ideas and I do some writing and stuff and then press the button and it goes. Mentally it goes out there somewhere. I don't know does anyone see it? No response: does anyone care?"

(Owston et al., 2008, p. 207) [55]

Also, often linked to discussions of presence, participation and responsiveness is the question of instructor and facilitation roles for online courses. Many pieces discuss the roles and values of facilitators to support discussion and collaboration. Dede et al. (2016) [53] devote a chapter (10) to the role and 'importance of moderators' within online STEM CPD, they describe their roles in online communities as being to: 'facilitate organization, welcome newcomers, encourage contributions, support top contributors, foster commitment, address problems and model good behavior' (p. 274). Expectations around participation, and preconceptions about these, seem to vary with teacher education modes as well as potentially being influenced by facilitators and formal or informal rules and etiquettes. Common rules relate to the expected frequency of contributing to fora and the need to respect the opinions and ideas of others (Keengwe and Kang, 2013) [64]. As with presence above, active participation is something often discussed and sometimes, but not always achieved in practice (Keengwe and Kang, 2013, p. 488) [64].

Getting the balance right between coordinated and/or mandated activity and spontaneous participation seems to be a common consideration in the literature. Lantz-Andersson et al. (2018, p. 310) [59] discuss how informally-developed online communities include a 'majority of participants that observed, without making any visible contribution (so-called lurkers).' And, at the other extreme, that the most active communities can often encroach on teachers' free time and leave many 'feeling 'overwhelmed' by the regular flow of information'. Whether or not this balance is well struck and/or whether communities are more formal or informal, as per Dede et al. (2016) [53], Lantz-Andersson et al. found moderators had a key role:

"Clearly no online community is ever spontaneous and an entirely un-organized 'bottom up' affair. In the studies on formally-organized online teacher communities, clear forms of leadership are seen as an implicit aspect of the institutional 
setup. However, even the most informally developed communities being studied were also found to depend on the sustained efforts of moderators ... In this sense, the apparent difficulty of controlling and planning the activities of all members in large online-groups challenges the extent to which opportunities exist for fostering active participation (cf., Macia \& Garcia, 2016) [58]."

(Lantz-Andersson et al., 2018, pp. 311-312) [59]

\subsubsection{Community Formation}

A theme within the teacher education principles relating to collaboration is the value of forming a professional learning community and working to orient teachers, and especially pre-service teachers, to participate within it. As touched on above, it is possible to wrap community elements around other (including more individualistic) teacher education approaches. Much attention is paid to culture and community development in the literature and reviews generally paint a positive picture of the potential to achieve this in online spaces. This can be seen in relation to online professional learning communities in LantzAndersson et al. (2018, p. 310) [59] where communities with a 'friendly, participatory culture' are supportive of experimentation, risk taking and searching discussion and feedback. This culture can take time to develop (as discussed in relation to video sharing and discussion in Perry et al., 2020) [35]. It is a relatively widespread view that community building and functioning benefits from (a) there being an 'established history of sharing and working together' outside of the program (Seddon et al., 2012, p. 436) [30] and (b) there being face-to-face sessions which take place prior to or in between online activity (i.e., within a blended format) (Seddon et al., 2012; Owston et al., 2008; Matzat, 2013; Keengwe and Kang, 2013) [30,55,64,68]. Face-to-face experience was considered by many as the 'glue' that creates a community, and increases rates of participation in subsequent online interaction (e.g., see Owston et al., 2008, p. 207) [55]. It is also worth noting that online spaces are discussed both as a hindrance for community development (as above) and as a benefit: Seddon et al. (2012, p. 435) [30] relate Beatty and Allix's (2005) [68] description of the potential advantages WebEx video conferencing technology in terms of its ability to 'transcend space and time', sustaining a larger group, and providing the ability to catch up on earlier content.

Overall, our reviews suggest that collaboration, including (emotional and pedagogical) support and belonging within professional learning communities is both possible and evident in remote and blended modes of teacher education, both formal or informal (but see Lantz-Andersson et al., 2018) [59], and for both novice and established teachers (LantzAndersson et al., 2018; Surrette and Johnson, 2015) [59,63]. The question is whether it is designed effectively to compensate for the lack of face-to-face interaction and as an intrinsic and important, structured element of the CPD that aligns with and realizes other principles of effective CPD.

\subsection{Diagnostics, Differentiation and Teacher Starting Points}

How can we 'differentiate' teacher education for teachers and their starting points? In relation to CPD more generally, we know for example that mentoring programs are particularly effective for providing personalized, targeted support and instruction and this can improve retention rates for early-career teachers (Fletcher-Wood and Zuccollo, 2020) [3]. To what extent are teacher diagnostics and differentiation possible within remote teacher education?

Modes that are built around the teacher education participants, such as mentoring or teacher-led discussion groups, lend themselves to diagnostics and differentiation in relation to teacher staring points. Similarly, where leaders and initial teacher educators can meaningfully guide and contribute to the teacher education, this allows the wider picture of a teacher's professional growth to be brought into focus and can manage overload, enabling teacher educators and leaders to focus in on fundamental points. Here we return to issues from previous sub-sections around (a) programme structure and its links to ownership 
and participation and (b) the ability to use video and/or multimedia to bring classroom practice and pupil outcomes to light within the teacher education space. Trade-offs are apparent in relation to content, structure and assessment:

Content - the greater range of content available, the more tailored it can be to support individual teacher needs; but with more content comes a greater risk of overload and difficulties supporting participants to focus in on and discuss fundamentals. Perhaps the most extreme examples here are the large resource bases/repositories and informal, open networks such as twitter communities. While we may find that there is 'something for everyone', including particularly specialist and specific content to be found-many (and particularly pre-service teachers) may feel overloaded, and content may not be accompanied with instruction (to help the teacher navigate and identify the key pedagogical features of the resource) nor opportunity to discuss these with others. Moreover, and again returning to the example of the APTC, the Share and Compare sections of the online programme were deliberately not pre-populated by instructors. There are benefits in terms of both ownership and depth of thinking of creating and developing ideas, resources and communities-or contextualising more generic content for one's own subject (Cordingley et al., 2018) [19] as compared to being met with 'off-the-shelf' content for all needs and pre-existing communities into which teachers must orientate and establish themselves.

Structure-The other point touched on in previous sections (e.g., Jamil and Hamre, 2018; Owston et al., 2008; Dede et al., 2016, Chapter 6) [51,53,55] is the use of structure to 'build-in' effective teacher education principles, including in this case opportunities for diagnostics (such as initial needs assessments, or implementation planning processes). Like with content, too much structure-particularly when used to maintain focus and mandate content (as opposed to design principles) — can reduce opportunities to tailor teacher education according to teachers' aspirations and starting points. Examples include self-study courses with set content. Similarly, our experience of MOOCs is that many have set content structured into weeks or modules, and provided by instructors, which are then 'softened' by the presence of community building features such as discussion boards. Equally, there are advantages to greater levels of structure, especially for initial teacher education, where it is possible to curate, sequence and ensure coverage of a core curriculum.

Assessment-Looking at the literature, great claims are made about the potential for personalized learning via technology in teacher education and education more generally. A widely advocated variant of this idea is that a combination of learning analytics (from simple scores to analysis through artificial intelligence and machine learning) and 'microcredentials' or units can make even the most structured and content-heavy programs highly accessible and differentiated for individual needs. Dede et al. (2016) [53], for example discuss the use of micro-credentials in the form of 'digital badges':

"A unique feature of digital badges is that they can easily be shared or aggregated, much like a professional portfolio, and the evidence behind the badge, since it is often also digital, can be examined to verify the value of the badge ... Technologies such as badges and analytics can help teachers map their personalized learning pathways, identify their progress along them and point to appropriate resources to support needed next steps."

(Dede et al. 2016) [53] (pp. 44-45)

There are several points within this general description: first, that micro-structures and credentials may allow more bespoke teacher education activity, perhaps at a cost of collaboration and guided support. Second, that multimedia technology can be used to connect and make accessible evidence relating to the learning to foster discussion and/or as a summative assessment. Third, micro-structures may indulge the concept of gamification. This is not something we discuss at any length here, but note that points, badges, levels and leader-boards are becoming ubiquitous features of many online spaces and are widely 
held to be beneficial features of learning design to encourage engagement and performance (Subhash and Cudney, 2018) [69].

A point raised in Qian et al. (2018) [70] worth noting here-one to which we return in relation to our discussion of curriculum and expertise below-is that the starting points of teachers in relation to subject knowledge and experiences within a topic area can influence their engagement with PD. Qian et al. (2018, p. 164) [70] found that novice, but subject-specialist teachers focused on material to develop their pedagogical content knowledge (PCK), non-subject-specialists focused on the content knowledge, and experience teachers were less likely to engage, believing that they had little need for the PD. This is an interesting point of contact between this section on differentiation for teachers, earlier discussions about the need for more experienced teachers to dial into and re-examine their extensive (and often tacit) expertise and experience, and the need for careful consideration of curriculum and employment of expertise.

One final point to note regarding teacher starting points not encountered within faceto-face teacher education is that teachers may be at different starting points with regards to their attitudes towards, experience of and skill with using technology and/or conducting teacher education remotely. This is born out in the available evidence around teacher satisfaction with online teacher education:

"Research indicates that course management systems are effective for those familiar with technology, but that user satisfaction diminishes as user familiarity with the technology declines."

(Elliot 2017, p. 121) [27] (Taylor, 2011; Tella, 2011; Thomas, 2010) [71-73]

\subsection{Theory and Practice, Experimentation and Contextualisation}

The next principle of effective teacher education relates to connecting theory with practice, and the reflection, and practical 'experimentation' that is needed to achieve this. This is often described in terms of active and contextualized learning (e.g., Darling-Hammond, 2017, p. v-vi) [21]. Again, rather than the details of this, our concern is the extent to which this can take place through remote or blended teacher education approaches. While the focus has been more on reflections than iterative development of practice as part of or alongside teacher education, the literature was broadly positive (Surrette and Johnson, 2015, p. 264; Lantz-Andersson's et al., 2018) [59,63]. Lantz-Andersson's et al. (2018) [59] review of formal and informal professional learning groups for example identifies numerous examples of groups that fostered reflection on practice. In some cases, it was felt that writing (rather than saying) responses 'was also seen to stimulate forms of reflection and self-analysis not evident in face-to-face meetings (Unwin, 2015) [74]' (p. 308). Moreover, links were found between online and face-to-face interaction for communities that had both an online and physical presence:

"For teachers working together in the same schools, increased visibility of colleagues' beliefs, thoughts, problems and evolving practices online created entry points for subsequent face-to-face dialogue."

(Lantz-Andersson et al., 2018, p. 308) [59]

Picking up themes noted in our earlier sections, Surrette and Johnson (2015) [63] found studies noting the benefits of being able to 'rewind and review the video and record more complete and accurate comments than is possible during real-time observations' (West et al., 2009, p. 384, quoted in Surrette and Johnson, 2015, p. 263) [63,75]. Using video, there is also a greater opportunity to conduct the reflections and discussions collaboratively, drawing on a greater number of examples (Perry et al., 2020) [35]. Other authors such as Keengwe and Kang (2013) [64] conclude that technological tools are important for integrating online and face-to-face learning and supporting learning to be put into practice, and also-as above- discuss the value of using technology to allow teachers to 'actively participate, communicate, and create their own materials' (p. 488). Tools discussed in the studies used by Keengwe and Kang (2013) [64] include multimedia CD-ROM, 'blackboard', web-based 
models and sites, wikis, online discussion and lectures, interactive white boards and Ning, a community building platform. We are also reminded of discussions of tools for teachers in Timperley et al. (2007) [76] and of 'smart tools' in Robinson et al. (2007) [77].

A key idea here is that (a) to combine theory and discussion, expert models of practice, and one's own practice requires focus and experimentation over time (see points around duration, below) and (b) sustaining this within teacher education benefits from artefacts, tools and technologies that bring practice and pupil learning (see pupil orientation section) together and across classroom and professional education spaces. This is as true for faceto-face as online/remote teacher education and, arguably, the latter has the affordance of a greater range of technology at one's fingertips to be able to achieve this. Related, and discussed further in the section below about sustained activity, is that the asynchronous teacher education approaches and content allows professional learning to run alongside and shape to classroom activity over time. Returning to the point made above, there is no guarantee that these exchanges lead to deep and critical reflection and discussion and-alongside the positive examples noted above-reviews provide numerous counterexamples:

"While these benefits were mostly intrapersonal in nature, studies did note a lack of critical discussion in the exchanges between teachers (e.g., Chen et al., 2009; Donnelly, 2010; Jarosewich et al., 2010; Prestridge, 2009) [78-81]. For example, participants were found to seldom challenge peers or engage in higher levels of analysis or reflection. When reviewing teachers' interactions in discussion forums, for example, the vast majority of responses to others' comments were found to be supportive without addressing the content of the course or furthering the discussion (Jarosewich et al., 2010) [80]"

(Lantz-Andersson et al., 2018, p. 308) [59]

\subsection{Curriculum and Specialist Expertise}

Here we consider a set of issues around how easy it is to incorporate expertise and create and sequence curriculum content within remote and blended teacher learning. When considering initial teacher education specifically, greater attention is required to the foundational curriculum and whether this 'covers' the fundamental skills and knowledge for teaching within the chosen subject area and educational context, as well as meets statutory duties, thereby providing a strong basis for ongoing early-career development and beyond. Moreover, there is a need to develop subject knowledge, which varies considerably by subject area and by phase (e.g., primary and secondary phases) (Cordingley et al., 2018, p. 19) [19]. Bringing this to our central question: to what extent is a subject-specific curriculum incorporating expert content and support possible in remote and blended modes of teacher education? Several responses to this question are apparent in the literature: first, authors note that online modes and technology can be used to bring together larger groups, which are more likely to incorporate and/or find it more economical to draw on specialist expertise (including top scientists, public figures and outstanding educational leaders and practitioners etc.), as well as develop subject-specific content. With larger-group modes such as MOOCs this is further accentuated, although Dede et al. (2016) [53] note that for MOOCs, splitting up by subject specialism sometimes reduces opportunities for cross-pollination of ideas and connection, which can come by splitting large groups by roles, interests and geography (e.g., when trying to establish a blended community in a local area). At the extreme, as they suggest, it is possible and, in many ways, beneficial to make group splits even more arbitrary, splitting by the first letter of the participant's city for example.

Overall, there seems to be a strong case that online teacher education, particularly when built around platforms and/or resource bases, and a strong curriculum content offer with specialist input is eminently possible, and indeed has many advantages over exclusively face-to-face approaches (including the ability of teachers to locate specific (e.g., 'just-in-time') content, fitted to their needs, and work through and engage with it 
individually or collectively in their own time. This connects to the above discussion around content and structure for differentiation, also to connecting theory and practice in their classroom. This is a familiar theme, which is echoed, as elsewhere, when our reviews come to consider curriculum content in online or blended teacher education, with both positive and negative examples discussed, such as points from Surrette and Johnson (2015, pp. 262, 264,266 ) [63] about content that is 'disconnected with their classroom practices' or 'are not aligned with district and state standards and assessments'.

\subsection{Duration and Organization}

The final teacher education principle addressed in this section is the value of approaches that are sustained over time and thereby enable fulfilment of earlier principles around meaningful connections with classroom practice and the need to gradually incorporate new thinking and practices into teaching repertoires. We hasten to add, however, that there are examples of more short-term teacher education programs, which when well-targeted and tightly specified can have significant and lasting impact (see Lauer et al., 2014, for a review focused on this specific question) [82]. Be that as it may, effective teacher education typically is sustained over time and establishes a rhythm of activities that give teachers time to practice, reflect on and embed techniques in their classrooms (Cordingley et al., 2015; Darling-Hammond, 2017) [18,21].

We note that the additional flexibility around timings (including remote and asynchronous participation) afforded in remote and blended learning approaches, combined with the use of technology and pedagogical/reflection 'smart' tools (see earlier) is a supportive factor for practicably sustaining teacher education over time. In this section, now this has been noted, we move on to discuss the question of flexibility versus structure for remote and blended teacher education design. Often the structure for professional learning is provided by a school curriculum, such as the AP Physics programme discussed above, or (and especially in the context of initial teacher education) a set of teacher standards (Elliott, 2017) [27]. There is an extended discussion of 'flexible design' for remote initial teacher education in Burns (2011, p. 138-139) [10], and how this can be accompanied with 'flexible delivery', where instructors look to tailor the programme to learner needs (see discussion of differentiation, above). Flexibility is frequently linked with convenience and the ability to tailor learning to meet individual teacher needs. For programs tightly structured around particular curricula, along with the benefits discussed above in terms of 'just-in-time' learning came practical problems of timing. As discussed in Owston et al. (2008) [55], teachers were often not teaching the same topics at the same time and a degree of alteration to teachers' plans was needed to fit in and align activity. As a general rule, flexibility around timings and online approaches helps teachers fit learning around their professional commitments and school timetables, avoid the need to use weekend days for group activity and better fit with personal circumstances. The only negative point in this area that we found in reviews was the concern in Lantz-Andersson et al. (2018, p. 312) [59] that 'flexibility also introduced a risk of 'never-ending' engagement, and online professional learning encroaching into teachers' non-work time and becoming an additional source of over-work'.

\section{Review of Empirical Evidence}

Question 3 (Q3). What empirical evidence is available that supports, refutes and/or refines our understanding of effective remote or blended teacher education (as per Question 2)?

a. Which forms or practices are identified as more/less effective?

b. What are the common features of effective approaches?

This section reports results from 24 empirical studies that met our inclusion criteria. The first 19 present empirical results (including evidence of impact or otherwise on pupils) of remote and/or blended teacher education programs. The final 5 include consideration of more than one mode (remote, blended and/or face to face) and thereby enable a 
form of comparison between modes. We summarize these 24 pieces within three broad groups. We also summarize results in relevant sections from one recent systematic review (Snell et al., 2019) [28], which presents a systematic review of 'technology-mediated language and literacy PD models' for teachers of early years (reception/kindergarten and pre-school) children. This review focused on random or quasi-randomized experimental studies, finding 11 in total.

\subsection{The Efficacy of Remote and Blended Teacher Education}

There are a group of studies that have evaluated remote or blended teacher education programs, measuring impacts on teachers and students. They are reviewed in this section. These do not seek to compare modality; indeed, for some, the fact that a remote or blended mode is used is incidental and raised only in specific results or discussion points. The studies reviewed below, provide us with some of examples of remote or blended programs that have been evaluated, and evidence of varying quality about whether they work or not.

\subsubsection{Coaching and Mentoring Interventions}

The evidence base for blended or remote coaching/mentoring of teachers was limited; however, there were a few high-quality, highly relevant studies. Allen et al. (2015) [83] present a study based on a stratified randomized controlled trial of the My Teaching PartnerSecondary (MTP-S) program, a web-mediated coaching program involving 86 secondary school teachers and 1194 secondary students. The program was conducted over 2 years involving 12 coaching cycles, where coaches selected extracts from the teachers' own lessons that they had videoed for the teachers to reflect on their pedagogical practices before discussing by telephone (Allen et al. 2015) [83]. Students' scores on the Virginia state standardized tests rose significantly (Effect Size $=0.48$ ) compared to controls.

In contrast, Kraft and Hill (2020) [84] reported on a web-based coaching programme designed to improve teaching of mathematics in relation to a Mathematic Quality of Instruction (MQI) framework using a 'MQI Coaching' model involving 'Cycles' of coaching using the MQI framework. The MQI is a well-validated instrument which provides a theory of action for the programme and a measure of specific aspects of teaching to target:

"A central element of our theory of action was that if teachers could learn to analyze instruction using the MQI's items and practice descriptors, they would (a) use more of the practices contained in those items and (b) strengthen the quality of these practices as implemented in their classrooms."

(Kraft and Hill, 2020. p. 5) [84]

The program involved 142 elementary and middle school teachers from 51 schools, supported by 24 expert MQI coaches (all with experience with the MQI, as classroom teachers and/or instructional coaches). Their randomized field trail indeed showed improved teaching using the MQI instrument and a higher likelihood of teacher retention for teaching maths, and in particular teaching maths in a grade (year group) with a high-stakes maths examination. Student gains (as effect sizes) however were estimated to be minimal, with estimated effects of $0.00(2 \mathrm{dp})$ on state tests, and 0.07 on a Measures of Academic Progress (MAP) test, neither of which were statistically significant. There were not clear reasons why student gains were not achieved/evidenced: the authors suggest issues of low statistical power, issues with standardized tests capturing all student learning and/or lack of program efficacy.

Snell et al. (2019) [28], the systematic review included in this section, reviewed evidence for various professional development programmes in language and literacy for teachers in early years settings. There were several areas of reporting:

- 'Remote, non-live, asynchronous coaching' - this included further studies of the My Teaching Partner (MTP) programme (as per Allen et al., 2015, above) [83]. Results were mixed, with Pianta et al. (2017) [85] and Mashburn et al. (2010) [86] finding 
mixed results on student learning outcomes, and Early et al. (2017) [87] not finding an impact on language or literacy outcomes.

- 'Remote live coaching' programmes, finding only one effective trial: Vernon-Feagans et al. $(2015,2013)[88,89]$ used remote live coaching with webcams and found effect sizes around 0.5 for four measures of reading ability for early years. Note that these studies also included other interventions, such as online materials and even a 3-day workshop for this last study.

- 'Enhancing' Tech PD with in-person coaching', where Landry et al. (2009) [90] found that in-person coaching i.e., a blended approach improved pre-school children's reading skills with effect sizes around 0.2 (CIRCLE study). But Jackson et al. (2006) [91] found mixed effects.

Our final study in this section is Rosenberg et al. (2020) [92], who reported on individual coaching for paraprofessionals (teaching assistants) about self-advocacy for students with disabilities. An initial 45-min individual teaching session was followed by distance bug-in-ear (BIE) coaching via the Zoom platform. They report improved student behavior but there were just four adult-student pairs and no controls. Nonetheless, it is interesting to note the study's use of advancing technology in the form of video conferencing and 'bug-in-ear' coaching tools.

\subsubsection{Mixed Component Interventions}

Having looked at mentoring and coaching interventions separately, we now turn our attention to other programs, noting the variety of approaches in use. The following studies are mostly reporting programs that combine instructional content and sessions, which deliver this with wrap-around teacher discussion and/or implementation tasks to promote application to classrooms. Given the relative small number of studies, we provide a short narrative summary of each study, providing an italicized summary of the main finding for each.

Ascetta, Harn \& Durán (2019) [93] reported on a brief (4-6 weeks, $\leq 1 \mathrm{~h}$ per week) online program that focused on: (a) teachers' self-monitoring and goal setting; and (b) language enhancement strategies to use in practice. They were interested in the impact of the type of feedback strategies used with the teachers, who were then randomly assigned to the type of feedback they received across the intervention: performance or self-report.

Finding: Regardless of feedback condition, all participating teachers increased their frequency of language enhancement strategy use, and all children had enhanced vocabulary skills performance.

Dash et al. (2012) [94] examined the impact of participation in online PD on 5th grade mathematics teaching. The PD consisted of 1 course per semester over three semesters, equating to approximately $70 \mathrm{~h}$ work per teacher. The delivery was asynchronous, with trained facilitators to monitor the completion of activities. It utilized a learning community model including readings, web-based resources, interactive on and offline activities, video, and peer-to-peer discussions. Teachers were required to implement a final project in their classrooms.

Finding: Participants in the PD scored significantly higher overall for pedagogical content knowledge than teachers in the control group and had greater gains in scores for overall pedagogical practices. However, no significant differences in changes in students' maths achievement were identified.

Our next study is Fishman et al., (2014b) [95] who report results from a survey of 6796 (Advanced Placement Curriculum) Biology teachers, which are matched to subsequent student scores. Teachers were provided with 'a range of professional development (PD) options, from week-long summer workshops to short face-to-face ( $\mathrm{FtF})$ courses, online self-paced courses, downloadable resources, and online peer-learning communities' and 'two high-quality PD offerings from outside providers included in this study.' (p. 3) There 
are limitations in methodology, including the inevitable self-selection in the extent to which teachers engage with the professional development and also complete the survey.

Finding: Overall, they find (p. 15) that 'some of the patterns of PD selected by teachers were predictive of student outcomes on the AP Biology exam, although effect sizes were small'.

Frumin et al. (2018) [61] undertook a 5-year longitudinal study of the participation of US high school science teachers in an online teacher community supporting curriculum change. The study focused on teachers' patterns of usage, the impact of usage on the performance of their students, and how the PLC might harmonize with established programmes of PD.

Finding: a clear association was found between teachers' participation and higher student examination scores, though causality could not be assumed. Interestingly, the frequency and duration of participation did not have a clear association with test scores. This project built on the earlier study by Fishman et al. (2014b) [95], as immediately above.

Goldenberg et al. (2014) [66] note the challenge of convening and supporting role-alike groups of teachers to provide specific training. They implemented a randomized control trial that focused on PD for Biology teachers to improve content knowledge, pedagogical knowledge and use of digital media in teaching. Teaching High School Biology was a fully online programme that included 4 sessions on teaching genetics and evolution using digital resources and inquiry-based approaches, utilizing readings, video clips, notebook work, discussion boards, and assignments.

Finding: The study found significant teacher knowledge increases despite high $(50 \%)$ teacher attrition rates, albeit no effect on student outcomes-perhaps because of difficulties measuring pupil outcomes from inquiry-based learning.

Griffin et al. (2018) [96] studied 32 elementary maths teachers for children with disabilities in the US participating in a PD programme called Prime Online. This consisted of 35 Moodle modules over 12 months with clear taught content, plus online discussions etc. with a focus on teacher beliefs (about maths teaching, students with disabilities and teacher inquiry) and teachers' mathematical knowledge.

Finding: Positive teacher impacts were found, but there was no impact on the students. There were no control conditions, and it is not clear which aspects of the programme were beneficial.

Steve Shaha has been involved in several related studies in this section. Shaha and Ellsworth (2013) [97] compared comparative gains (from one year to the next) in mathematics and reading standardized assessments for school with teachers with high levels of engagement with $P D$ 360, which 'offers a large library of expert-produced training videos, powerful support tools and resources, and an online professional learning community of nearly one million educators' (p. 176). 169 schools were selected and compared with average gains for their Districts.

Finding: Students in these schools experienced $18.9 \%$ increases in mathematics scores versus $4.2 \%$ for their districts, and $15.3 \%$ increases in reading versus $2.5 \%$ for their districts. Shaha, Glassett and Copas (2015b) [98] showed that these gains were further extended with an additional follow-up year. Similarly, Shaha, Glassett, Ellsworth (2015d) [99] suggest the greater the number of years of high participation in the programme, the bigger the effect (also see Shaha et al., 2015a; 2015c; 2016) [100-102]. With all of these studies, without randomization to receive the program, these gains may reflect teacher self-selection into their degree of engagement with the programs and/or general school characteristics rather than PD 360 per se.

Walker et al. (2012) [103] looked at 2 designs for online PD to help teachers learn to create online activities for students. One focused solely on technology skills to design student activities using online resources, while the other coupled technology skills with learning to design PBL activities for their students using online resources. The quasiexperimental study involved 36 mathematics and science junior high school teachers (51 initially signed up) and 1247 students over a sustained period of 3 months. 
Finding: Both designs showed significant gains in 'self-reported knowledge, skills, and technology integration' for teachers. There were also 'self-reported gains in behaviour, knowledge, and attitudes' for all students, though those taught by PBL teachers scored greater gains on behavior and knowledge. PBL teachers had larger gains in PBL knowledge and use than the tech-only teachers. Limitations included the fact that teachers selected the class to administer the student survey; students may have provided socially desirable responses and there was potential for pre-existing differences between treatment groups, such as prior exposure to PBL.

The final study reported in this sub-section is Weschke, Barclay \& Vandersall (2011) [104], who undertook a small-scale study of 31 elementary teachers who completed a fully online master's programme focused on pedagogy and literacy matched with a comparative sample of 39 teachers with an existing masters level qualification who did not complete the online programme. The study looked at the impacts on oral reading fluency of students as a measure of efficacy by undertaking 3828 student observations. It was an attempt to establish the impact on the education community of a high demand and fully online programme.

Finding: Hierarchical linear modelling was used to understand the longitudinal effects of teachers on student learning. The findings indicated a significant positive effect of the online program on student achievement. However, the results were not constant across different elementary grades. The study suggests more research needs to be conducted on why student outcomes resulting from online PD vary according to age and stage.

\subsubsection{Interventions for Student Behaviour}

There were two studies that focused on student behavior that met our general eligibility criteria, but these are different in kind to other studies, so are not reported here (Marquez et al., (2016); Hoffman et al., 2020).

\subsection{Comparing the Effectiveness of Teacher Education Modes}

In this section we review five studies, a meta-analysis (Hill et al., 2020) [5] and a systematic review (Snell et al., 2019), all of which present results that allow comparison of the effectiveness of teacher education modes or combinations of them.

An early study in this area is Fisher et al. (2010) [105] who compare a virtual workshop with an actual workshop, both focused on developing a Concept Mastery Routine (CMR). The study recruited 59 certified teachers and randomly allocated them to one of the two groups. The virtual workshop (VW) made use of a school's computer 'lab' and a multimedia software programme. The face-to-face session (the 'actual workshop' - AW) in the classroom was set up with 25 to 30 seats in rows. To ensure comparability in other respects, both VW and AW had an instructor's computer, data projector, a screen and whiteboards; the AW translated this material into PowerPoints and other documents, and made use of the video clips form the multi-media CD in the session.

Finding: Comparisons of pre and post test data show that there is no difference in student tests of concept knowledge between the students of teachers who participated in the face to face or virtual PD, although teachers expressed slightly more satisfaction from face-to-face PD.

Another early study, one that received considerable attention in the literature (see discussion section) is Fishman et al. (2013) [106]. This was a randomized experiment involving a total of 49 teachers that explicitly set out to compare online and face to face professional development. The PD aims to prepare high school teachers to implement a year-long environmental science curriculum, increasing the probability that curriculum enactment is consistent with original design and outcomes. Teachers either received a week-long ( $48 \mathrm{~h}$ ) course spread over 6 days, consisting of face-to-face workshop sessions or an online alternative 'to be completed by teachers asynchronously at their own pace', consisting of a series of 'short courses with a facilitator guiding teachers and answering questions as they worked through the materials' (pp. 429-430). 
Finding: Fishman et al. (2013) [106] find increases in subject knowledge for both online and face-to-face groups, with little difference in the gains between the two (controlling for pre-test scores) and no differences between the conditions in relation to a range of teacher attitudinal measures. In relation to student outcomes on an environmental science scale, the students of teachers in the online condition improved by just over half a standard deviation, the students in the face-to-face condition, one smaller than half a standard deviation, but the difference between these was not statistically significant. One especially notably finding within the study was the lack of a relationship between 'contact hours' and student performance in the online condition.

"Because we found no relationship between amount of time teachers spent on online PD and our outcome measure, we conclude that teachers who completed online PD more rapidly required less time to benefit from materials. Online PD does not have to be 'one size fits all' in terms of participation."

(Fishman et al., 2013, p. 435) [106]

The next study we examine is Rock (2017) [107]. This doctoral thesis presents results retrospectively comparing student assessment scores for students of teachers who participated in online or face to face state-grant-funded professional development. The study looks at whether the mode of PD delivery was associated with student outcomes of pupils taught by the sample of 216 elementary teachers and 216 high school teachers. In overview, 105 of these teachers engaged in F2F PD and 327 took part in online sessions.

Finding: The results found no statistically significant difference between the two modes of PD in terms of student impact, concluding that, 'when the content of professional development is comparable, the form of professional development and the level of instruction have minimal effect on student learning outcomes.' (p. 186)

Webb, Nickerson and Bush (2017) [108] present comparative analysis of student survey responses $(n=4832)$ between teachers $(n=75, K-12)$ who undertook different modes of professional development in the context of a computer science (game design) curriculum.

Finding: There were very little difference across the survey items when comparing students of teachers who received professional development in different modes. The authors do make a helpful distinction between Massive, Open, Online Courses (MOOCs) and managed online PD with smaller groups. They state that their completion rate $(60 \%)$ is higher than that found in typical MOOCs and accredit this to the ability to develop a sense of community and provide facilitator support in smaller groups.

The final individual study reported in this section is Russell et al. (2009) [109]. The study compared the effects of a professional development course for teachers of maths in grades one to five in an online and a face-to-face format. Participants were randomly assigned to one of the conditions, both delivered over the same eight-week period (see Russell et al., 2009, pp. 74-75, for further details of the intervention) [109].

Finding: Using a range of data sources, the authors find that, 'both formats of the course showed significant impacts on teachers' mathematical understanding, pedagogical beliefs, and instructional practices' (p. 71). Student outcome data were minimal, although enough to meet our eligibility criteria, and were only collected through a student survey. This student survey asked about instructional practices of the teachers and their quality; no statistically significant differences were found between online and face-to-face groups.

Finally, we review results from Hill et al.'s (2020) [5] meta-analysis of STEM PD and Snell et al. (2019) [28]. We only provide a single result from Hill et al. (2020) [5] as the report is focused on CPD in general-but this result is a significant one. They present meta-analysis of the effect of STEM professional learning programs according to various PD characteristics relating to its development, type, focus and-pertinent for our review-format. Regarding the latter, standardized effects from a total of 95 studies of professional development (including six which provided curriculum materials) were summarised in terms of the average percentile rank for intervention students compared to control/comparison students in the 50th percentile. 
Finding: Their results on program format, looking across the 95 studies within the meta-analysis suggest that 'Any Online PD' (i.e., not entirely face-to-face) tends to have positive, but lower effects than other formats, with about half the overall increase (see Hill et al., 2020, Figure 4, p. 54) [5]. Whether this is reflective of the quality of the online programs or is something related to the mode per se is difficult to determine from this brief and 'high-level' view meta-analysis. A fair comparison between modes would deliver the same content through more than one mode, rather than programs that 'naturally' do or do not include an online element (which may be of a different nature or quality for reasons other than the mode).

Finally, we examine the systematic review reported in Snell et al. (2019) [28]. This reviewed evidence for various professional development programs in language and literacy for teachers in early years settings. They report studies from across our remote and blended approaches $(\mathrm{Q} 1$, above). Here we focus only on results that compare CPD modes or difference remote and blended approaches.

Finding: In overview, Snell et al. (2019) [28] conclude their review as follows:

"These results also showed that Tech PD programs can be as effective as in-person PD programs, with effect sizes in the moderate to large range for impacts on teaching practices (i.e., Cohen's $\mathrm{d}>0.5$ ) and in the small to moderate range for impacts on student learning (i.e., Cohen's $d=0.2-0.5$ ). These studies may also suggest that the PD content was well developed and tested and that the technology was successfully used as method of dissemination ... In most of the Tech PD studies, not all measured outcomes showed positive results. Sometimes the effects were similar between in-person PD and Tech PD, and sometimes this similarity was reflected in null effects for either condition."

(Snell et al., 2019, p. 216) [28]

\section{Conclusions}

\subsection{Main Findings and Contributions of This Review}

In each of the sections above, we have summarized and drawn conclusions about the main findings arising from our analysis. Here we consider the more general question of whether remote and online teacher education can be considered to be effective, based on theory and evidence, and-if so-in what respects it is likely to be superior or inferior to face-to-face teacher education. Given the limited robust evidence to base this answer on (see Seciton 5), our conclusion is inevitably only tentative and general. We also, therefore, briefly comment on our present understanding, in terms of theory and evidence, of effective remote and blended teacher education.

Question 4 (Q4). Implications and Unknowns-What, if any, general principles for effective online or blended teacher education are evident?

a. What does the evidence suggest about the relative effectiveness of teacher education modalities (including in comparison with the face-to-face mode)?

b. What are the main areas of uncertainty and gaps in our present understanding?

\subsection{Relative Effectiveness of Teacher Education Modality}

Remote and blended teacher education is a relatively new field of practice and study. There are few studies that enable firm conclusions to be drawn on the relative effectiveness of modes and approaches. We therefore return to our discussion of the question itself that we began near the opening of the Approaches and Limitations (Q2) section, where we asked whether the focus should be on the 'medium' (i.e., the mode and approaches to remote and blended teacher education) or the 'message' (i.e., the quality of the teacher education itself with respect to research-informed principles). We concluded that-while there is value in examining the former (especially given recent technological advances and 
the present circumstances surrounding the COVID-19 pandemic), we must not lose sight of the latter.

Having now reviewed the literature and evidence, we believe that this position still stands. We also note a similar reticence to draw conclusions about modes per se-given too little systematic testing and the large variation in the nature and quality of remote and blended programs-is also evident in the literature:

"We do not believe that the PD described in this study, whether online or faceto-face, is representative of all PD. Yet there is a tendency, especially among educational decision makers, to treat 'online' PD as if it represents a particular approach, rather than a delivery vehicle. There is a need for studies that examine many different designs for PD: 'online' and 'face-to-face' are no more descriptive in the end than 'workshop' in terms of understanding the nature of the teaching and learning activities contained within the PD."

(Fishman et al., 2013, p. 436) [106]

We agree. While we hold that there is value in examining 'delivery vehicles' and their respective affordances and limitations, it is likely-especially when considering blended or multi-approach teacher education and the growing ubiquity of technology (especially video for conferencing and lesson observation) — that differences in medium will not be the main consideration for teacher education quality: programs will tend towards a blend of media and approaches and their distinguishing quality factors will relate to teacher education principles and whether these have been achieved rather than the mode.

That said, let us address the question nonetheless: what does the evidence suggest about the relative effectiveness of teacher education modes? The few studies we have to go on (i.e., which allow fair comparison between similar content in different modes or combination of approaches) suggest that there is little difference in effectiveness (Fisher et al., 2010; Fishman et al., 2013; Rock, 2017; Webb et al., 2017; Russell et al., 2009) [105-109]. This includes studies presenting results from randomized experimental designs assessing impact on teachers' student's attainment (Fisher et al., 2010; Fishman et al., 2013) [105,106]. In the closest systematic review to our own, focused on language and literacy PD in the early years, Snell et al. (2019, p. 216) [28] conclude 'that Tech PD programs can be as effective as in-person PD programs'. There are tantalizing findings about combining components such as coaching and mentoring with video lesson observations, curriculum materials and/or CPD—but with such a limited evidence base, drawing conclusions would be over-reaching.

\subsection{Design Principles for Teacher Education Modality}

Anticipating limitations in the evidence, our approach has included more theory-rich and exploratory sections where we have drawn on reviews and selected empirical pieces to explore what effective remote and blended teacher education might look like in terms of its use of technology and learning design. As we first noted in the introduction, back in 2014, researchers (e.g., see Fishman et al., 2014a; Moon et al., 2014) [15,95] were in agreement that the field would benefit from scholarship that leads to 'research-based design principles to guide the ongoing development, implementation, and evaluation efforts in online PD'. Six years on, we have been able to report on a larger, but still limited literature. Even in the most highly researched areas, such as around professional learning communities (see Lantz-Andersson et al., 2018) [59], more research is needed. A similar appraisal of the literature on online ITE is provided by Dyment and Downing (2020) [11], as follows:

" ... the present research base is fragmented and consists of disparate and unrelated studies that rarely cross reference each other. Given that no particular author is dominating the publishing landscape for ITE, we suspect that, for most authors, these articles represent scholarship of their own teaching and learning, as they report through scholarly publications on a particular innovation or trend in their practice. We do not wish to be overly critical of this fragmented 
approach to research; we feel confident that these studies would nevertheless have had a small sphere of influence on the practices of the teacher educators who performed the research, also on their local colleagues and, hopefully, other readers of the journal ... We believe that there is an urgent need for a more strategic, cohesive, and collaborative approach to researching online ITE. Researchers must be encouraged to work together to establish a shared research agenda that tackles the 'harder-to-reach' variety of research questions. This will require leadership, coordination, and collaboration. If successful, this would allow interdisciplinary teams, with diverse research experience and cross-cultural expertise, to develop broader and more relevant insights than is possible when individual researchers simply profile their own 'innovation' — again and again ... "

$$
\text { (Dyment and Downing, 2020, p. 329-330) [11] }
$$

There were, however, notable exceptions: we did find strong examples which provide the rigorous evidence and theoretical depth needed for progress, including Surrette and Johnson's (2015) [63] meta-analysis which concludes favorably about the question of whether online environments have the ability to facilitate key professional development principles; Dyment and Downing's (2020) [11] systematic review of the literature on online ITE; the systematic review from Snell et al. (2019) [28] identifying 11 experimental or quasi-experimental studies; and well-designed evaluation studies including Kraft and Hill (2020) [84] and Allen et al. (2015) [83]; and several other pieces which we discussed in previous sections. It is on such reviews and studies that conclusions about effectiveness can start to be founded. We hope we have added to this through our blend of theory application, review synthesis and systematic evidence assessment.

The affordances and limitations section is replete with principles and considerations for the design of remote and blended teacher education. This, however, is almost exclusively based on perspectives from across the literature coupled with interpretations of our own, which enjoy varying levels of evidential support-support that becomes more tenuous as one takes the principle further from the study context and focus from which it originated. Of particular concern when it comes to evidential support was the lack of studies that reported student outcomes (in any form whatsoever). Given that a pupil orientation is a feature of effective professional learning, this lack of attention to how teacher education affects pupils impairs our ability to assess both process and impact of teacher education programmes. Evaluating the impact of teacher education on pupils is central to establishing evidence-based principles for effective policy, programmes and practice.

The set of principles, affordances and limitations described in this report, therefore, can be seen as both a statement from the literature of working principles for online or blended teacher education design at the same time as a set of hypotheses and research questions that are yet to be established and need to be tested and developed through teacher education research and practice. So, while many plausible principles are apparent, we simply do not have firm evidence back these up at present. However, we do think that the literature suggests that remote and blended teacher education show considerable promise; that they have distinct advantages and disadvantages relative to solely face-to-face approaches; and that they already are and are likely to increasingly become important parts of the teacher education landscape.

Supplementary Materials: The following are available online at https:/ /www.mdpi.com/article/10 .3390/educsci11080453/s1, References organized by review database group.

Author Contributions: Conceptualization, T.P., M.F. and P.C.; methodology, T.P. and P.C.; formal analysis, T.P., M.F. and P.C.; data curation, T.P.; writing—original draft preparation, T.P., M.F. and P.C.; writing-review and editing, T.P., M.F. and P.C.; project administration and funding acquisition, T.P. All authors have read and agreed to the published version of the manuscript.

Funding: This research was funded by STEM Learning, commissioned through University of Birmingham Enterprise Limited. 
Institutional Review Board Statement: Not applicable.

Informed Consent Statement: Not applicable.

Data Availability Statement: Not applicable.

Acknowledgments: We would like to thank STEM Learning for commissioning this review, and for their support with review scoping, screening and write up, colleagues in the Department of Teacher Education, University of Birmingham, and Centre for the Use of Research and Evidence in Education (CUREE), UK.

Conflicts of Interest: The authors declare no conflict of interest.

\section{Appendix A. Search Term Record}

\begin{tabular}{|c|c|c|}
\hline Database & Search String/Details & Results \\
\hline $\begin{array}{l}\text { Web of Science } \\
\text { (10 collections) }\end{array}$ & $\begin{array}{c}\left(\mathrm{TI}=\left(\text { teach* OR educat* OR profession*) AND AB }=\left(\text { educat }^{*} \text { OR learn* OR }\right.\right.\right. \\
\text { CPD OR train* OR develop*) AND TI = (review OR “meta-analysis" OR } \\
\text { synthesis OR Evaluation OR Trial OR Impact OR effect) AND AB = (modality } \\
\text { OR mode OR online OR “face-to-face" OR blended OR remote OR virtual OR } \\
\text { distance)) AND LANGUAGE: (English) Indexes = SCI-EXPANDED, SSCI, } \\
\text { A\&HCI, CPCI-S, CPCI-SSH, BKCI-S, BKCI-SSH, ESCI, CCR-EXPANDED, IC } \\
\text { Timespan = 2005-2020 }\end{array}$ & $\begin{array}{l}3314 \text { initial } \\
1400 \text { after exclusion by } \\
\text { WoS categories }\end{array}$ \\
\hline $\begin{array}{l}\text { Proquest } \\
\text { (9 databases see } \\
\text { record) }\end{array}$ & $\begin{array}{c}\text { TI: (teach* OR educat* OR profession*) } \\
\text { AND TI: (educat* OR learn* OR CPD OR train* OR develop*) } \\
\text { AND TI: (modality OR mode OR online OR “face-to-face" OR blended OR } \\
\text { remote OR virtual OR distance) } \\
\text { AND AB: (review OR “meta-analysis" OR synthesis OR Evaluation OR Trial } \\
\text { OR Impact OR effect) } \\
\text { Language: English } \\
\text { Date: } 2010 \text { onwards }\end{array}$ & 3638 results \\
\hline \multicolumn{3}{|c|}{ Supplementary Searches } \\
\hline Google Scholar & $\begin{array}{c}\text { allintitle: (teacher OR educator OR practitioner) (modality OR mode OR online } \\
\text { OR “face-to-face" OR blended OR remote OR virtual OR distance) } \\
\text { Date: } 2005+\end{array}$ & $\begin{array}{l}6390 \text { results } \\
\text { (Limited to first } 1000 \\
\text { results) }\end{array}$ \\
\hline Google Scholar & $\begin{array}{l}\text { allintitle: (teacher OR educator OR practitioner) (modality OR mode OR online } \\
\text { OR “face-to-face” OR blended OR remote OR virtual OR distance) (trial OR } \\
\text { RCT OR random OR experiment OR randomised OR quasi-experiment) }\end{array}$ & $\begin{array}{c}24 \text { results } \\
\text { (19 retrieved) }\end{array}$ \\
\hline Google Scholar & 'Pearl growing' using citation data for 15 relevant papers & $\begin{array}{c}839 \text { results } \\
\text { (64 retrieved) }\end{array}$ \\
\hline Ingenta Connect & $\begin{array}{c}\text { Title, Keywords or Abstract contains: } \\
\text { teacher AND (development OR learning OR training) AND (modality OR } \\
\text { mode OR online OR “face to face" OR blended OR remote OR virtual OR } \\
\text { distance) AND (review OR “meta-analysis" OR synthesis OR Evaluation OR } \\
\text { Trial OR Impact OR effect) }\end{array}$ & $\begin{array}{l}193 \text { results } \\
\text { (Initial screening on } \\
\text { title-26 met criteria, } \\
24 \text { items retrieved) }\end{array}$ \\
\hline JSTOR & $\begin{array}{c}\text { ((ti:((teach* OR educat* OR profession*)) AND ti:((educat* OR learn* OR CPD } \\
\text { OR train* OR develop*))) AND ti:((modality OR mode OR online OR } \\
\text { "face-to-face" OR blended OR remote OR virtual OR distance))) } \\
\text { Subject: Education } \\
\text { Date: } 2010 \text { onwards }\end{array}$ & $\begin{array}{l}214 \text { results } \\
\text { (Initial screening on } \\
\text { title- }-17 \text { results } \\
\text { selected; } 16 \text { results } \\
\quad \text { retrieved) }\end{array}$ \\
\hline
\end{tabular}




\section{Appendix B. Inclusion and Exclusion Criteria}

\begin{tabular}{|c|c|c|}
\hline Area & Include/Exclude & When Applied? \\
\hline Date & Include-Studies conducted in or after 2005 & Searching \\
\hline Learners & Include-All age 3-18 (Inc. SEN and mainstream) & Screening title and abstract \\
\hline Teacher learning focus & $\begin{array}{l}\text { Include-Substantial focus on teacher learning and/or improving } \\
\text { pupil outcomes via teacher learning. There must be a teacher } \\
\text { learning element. } \\
\text { Include-Teachers defined as all subjects, all career states (qualified, } \\
\text { unqualified), all statuses (including teaching assistants). }\end{array}$ & Screening title and abstract \\
\hline $\begin{array}{c}\text { Non-face-to-face } \\
\text { element }\end{array}$ & $\begin{array}{l}\text { Include-All empirical and theoretical pieces which present findings } \\
\text { about a mode of teacher learning other than face-to-face. This can be } \\
\text { a trial of an online or blended CPD programme. It would ideally } \\
\text { include a comparison of face-to-face and another mode of teacher } \\
\text { learning (but an evaluation of a single remote or blended mode is } \\
\text { acceptable). } \\
\text { Also Include-Reviews, meta-analyses or reports-if they are focused } \\
\text { on effective CPDL or ITE and have potential implications (either due } \\
\text { to sub-results or by inference from principles) for remote or blended } \\
\text { teacher education. }\end{array}$ & Screening full text \\
\hline Pupil outcomes & $\begin{array}{l}\text { Include-All studies included in the main review must present some } \\
\text { empirical evidence about the impact of the teacher learning on pupil } \\
\text { outcomes. This is to be interpreted broadly and can include, e.g., } \\
\text { classroom observations or other data collections reporting pupil } \\
\text { behaviours, perspectives and/or learning outcomes. }\end{array}$ & Screening full text \\
\hline
\end{tabular}

Appendix C. Record of Search Results and Screening

\begin{tabular}{cc}
\hline Search Databases & \\
\hline Web of Science & 1400 \\
Proquest & 3638 \\
Google Scholar & 1000 \\
Google Scholar & 24 \\
Goole Scholar (pearl) & 839 \\
Ingenta Connect & 193 \\
JSTOR & 214 \\
Other Additions & 46 \\
Total Records & 7354 \\
\hline
\end{tabular}




\begin{tabular}{|c|c|c|c|c|c|c|c|c|c|c|c|c|}
\hline & \multirow[b]{2}{*}{ Before } & \multicolumn{9}{|c|}{ Exclusion } & & \multirow[b]{2}{*}{ Retained } \\
\hline & & $\begin{array}{l}\text { Not } \\
3-18\end{array}$ & $\begin{array}{l}\text { Not } \\
\text { TD }\end{array}$ & $\begin{array}{c}\text { No } \\
\text { Remote } \\
\text { PD Ele- } \\
\text { ment }\end{array}$ & $\begin{array}{l}\text { Dupli- } \\
\text { cate }\end{array}$ & $\begin{array}{c}\text { No } \\
\text { Pupil } \\
\text { Out- } \\
\text { come }\end{array}$ & $\begin{array}{l}\text { Pre- } \\
2005\end{array}$ & $\begin{array}{l}\text { Inac- } \\
\text { cessible }\end{array}$ & $\begin{array}{c}\text { Not } \\
\text { English }\end{array}$ & $\begin{array}{l}\text { Total } \\
\text { Exc }\end{array}$ & & \\
\hline $\begin{array}{l}\text { After round } \\
1 \text {-title } \\
\text { screening }\end{array}$ & 7354 & & & 5638 & & & & & & 5638 & & 1716 \\
\hline $\begin{array}{l}\text { After round } \\
2 \text { - title and } \\
\text { abstract }\end{array}$ & 1716 & 160 & 515 & 52 & & & & & & 727 & & 989 \\
\hline \multirow[t]{2}{*}{$\begin{array}{l}\text { After round } \\
3-\text { full text }\end{array}$} & 989 & 28 & 50 & 32 & 45 & 749 & 5 & 4 & 3 & 916 & & 73 \\
\hline & & & & & & & & & & & $\begin{array}{l}\text { Late } \\
\text { En- } \\
\text { tries }\end{array}$ & \\
\hline $\begin{array}{l}\text { Reviews and } \\
\text { Reports }\end{array}$ & 25 & & & & 6 & & & & & 6 & 3 & 22 \\
\hline $\begin{array}{l}\text { Empirical } \\
\text { Studies }\end{array}$ & 25 & & & & 2 & & & & & 2 & 1 & 24 \\
\hline \multirow[t]{2}{*}{$\begin{array}{l}\text { Background } \\
\text { and Wider }\end{array}$} & 23 & & & & 4 & & & & & 4 & 0 & 19 \\
\hline & & & & & & & & & & Total & & 65 \\
\hline
\end{tabular}

\section{References}

1. Slater, H.; Davies, N.M.; Burgess, S. Do teachers matter? Measuring the variation in teacher effectiveness in England. Oxf. Bull. Econ. Stat. 2012, 74, 629-645. [CrossRef]

2. Kane, T.J.; McCaffrey, D.F.; Miller, T.; Staiger, D.O. Have We Identified Effective Teachers? Validating Measures of Effective Teaching Using Random Assignment; Bill \& Melinda Gates Foundation: Seattle, WA, USA, 2013.

3. Fletcher-Wood, H.; Zuccollo, J. The Effects of High-Quality Professional Development on Teachers and Students: A Rapid Review and Meta-Analysis; Education Policy Institute: London, UK, 2020.

4. Kraft, M.A.; Papay, J.P. Can Professional Environments in Schools Promote Teacher Development? Explaining Heterogeneity in Returns to Teaching Experience. Educ. Eval. Policy Anal. 2014, 36, 476-500. [CrossRef] [PubMed]

5. Hill, H.C.; Lynch, K.; Gonzalez, K.E.; Pollard, C. Professional development that improves STEM outcomes. Phi Delta Kappan 2020, 101, 50-56. [CrossRef]

6. Tschannen-Moran, M.; Hoy, A.W. Teacher efficacy: Capturing an elusive construct. Teach. Teach. Educ. 2001, 17, 783-805. [CrossRef]

7. Cordingley, P.; Crisp, B.; Johns, P.; Perry, T.; Campbell, C.; Bell, M.; Bradbury, M. Constructing Teachers' Professional Identities. Available online: https://issuu.com/educationinternational/docs/2019_ei_research_constructing_teach (accessed on 18 August 2021).

8. Hobbs, A.; Bolan, F. Distance Learning, POSTNote Parliamentary Research Briefing. Available online: https:/ post.parliament. uk/research-briefings/post-pn-0639/ (accessed on 18 August 2021).

9. La Velle, L.; Newman, S.; Montgomery, C.; Hyatt, D. Initial teacher education in England and the COVID-19 pandemic: Challenges and opportunities. J. Educ. Teach. 2020, 46, 596-608. [CrossRef]

10. Burns, M. Distance Education for Teacher Training: Modes, Models, and Methods; Education Development Center Inc.: Washington, DC, USA, 2011.

11. Dyment, J.E.; Downing, J.J. Online initial teacher education: A systematic review of the literature. Asia-Pac. J. Teach. Educ. 2019, 48, 316-333. [CrossRef]

12. Le Cornu, R. Key Components of Effective Professional Experience in Initial Teacher Education in Australia; Australian Institute for Teaching and School Leadership: Melbourne, Austrilia, 2015.

13. Dede, C.; Jass Ketelhut, D.; Whitehouse, P.; Breit, L.; McCloskey, E.M. A Research Agenda for Online Teacher Professional Development. J. Teach. Educ. 2008, 60, 8-19. [CrossRef]

14. Fishman, B.; Konstantopoulos, S.; Kubitskey, B.W.; Vath, R.; Park, G.; Johnson, H.; Edelson, D. The Future of Professional Development Will Be Designed, Not Discovered. J. Teach. Educ. 2014, 65, 261-264. [CrossRef]

15. Moon, J.; Passmore, C.; Reiser, B.J.; Michaels, S. Beyond comparisons of online versus face-to-face PD: Commentary in response to Fishman et al.,"Comparing the impact of online and face-to-face professional development in the context of curriculum implementation". J. Teach. Educ. 2014, 65, 172-176. [CrossRef] 
16. Quinn, F.; Charteris, J.; Adlington, R.; Rizk, N.; Fletcher, P.; Reyes, V.; Parkes, M. Developing, situating and evaluating effective online professional learning and development: A review of some theoretical and policy frameworks. Aust. Educ. Res. 2019, 46, 405-424. [CrossRef]

17. Cordingley, P. The contribution of research to teachers' professional learning and development. Oxf. Rev. Educ. 2015, 41, 234-252. [CrossRef]

18. Cordingley, P.; Higgins, S.; Greany, T.; Buckler, N.; Coles-Jordan, D.; Crisp, B.; Saunders, L.; Coe, R. Developing Great Teaching: Lessons from the International Reviews into Effective Professional Development; Durham University: Durham, UK, 2015.

19. Cordingley, P.; Greany, T.; Crisp, B.; Seleznyov, S.; Bradbury, M.; Perry, T. Developing Great Subject Teaching: Rapid Evidence Review of Subject-Specific Continuing Professional Development in the UK; CUREE Limited: London, UK, 2018.

20. Cordingley, P.; Higgins, S.; Greany, T.; Crisp, B.; Araviaki, E.; Coe, R.; Johns, P. Developing Great Leadership of CPDL. Available online: http:/ / www.curee.co.uk/files/publication/\%5Bsite-timestamp\%5D/Developing\%20Great\%20Leadership\%20CPDL\% 20-\%20final\%20summary\%20report.pdf. (accessed on 18 August 2021).

21. Darling-Hammond, L.; Hyler, M.E.; Gardner, M. Effective Teacher Professional Development; Learning Policy Institute: Palo Alto, CA, USA, 2017.

22. Rogers, S.; Brown, C.; Poblete, X. A systematic review of the evidence base for professional learning in early years education (The PLEYE Review). Rev. Educ. 2019, 8, 156-188. [CrossRef]

23. Hargreaves, D.H. A common-sense model of the professional development of teachers. In Reconstructing Teacher Education: Teacher Development; Elliot, J., Ed.; Falmer: London, UK, 1993.

24. DfE. ITT Core Content Framework. Available online: https://www.gov.uk/government/publications/initial-teacher-trainingitt-core-content-framework (accessed on 18 August 2021).

25. Little, C.A.; Housand, B.C. Avenues to professional learning online: Technology tips and tools for professional development in gifted education. Gift. Child Today 2011, 34, 18-27. [CrossRef]

26. Bower, M. Deriving a typology of $\mathrm{W}$ eb 2.0 learning technologies. Br. J. Educ. Technol. 2016, 47, 763-777. [CrossRef]

27. Elliott, J.C. The Evolution From Traditional to Online Professional Development: A Review. J. Digit. Learn. Teach. Educ. 2017, 33, 114-125. [CrossRef]

28. Snell, E.K.; Hindman, A.H.; Wasik, B.A. A review of research on technology-mediated language and literacy professional development models. J. Early Child. Teach. Educ. 2019, 40, 205-220. [CrossRef]

29. Horn, M.B.; Staker, H. The Rise of K-12 Blended Learning. Available online: http:/ /www.innosightinstitute.org/innosight/wpcontent/uploads/2011/01/The-Rise-of-K-12-Blended-Learning.pdf (accessed on 18 August 2021).

30. Seddon, K.; Postlethwaite, K.; James, M.; Mulryne, K. Towards an understanding of the learning processes that occur in synchronous online seminars for the professional development of experienced educators. Educ. Inf. Technol. 2011, 17, 431-449. [CrossRef]

31. Kraft, M.A.; Blazar, D.; Hogan, D. The Effect of Teacher Coaching on Instruction and Achievement: A Meta-Analysis of the Causal Evidence. Rev. Educ. Res. 2018, 88, 547-588. [CrossRef]

32. National Framework for Mentoring and Coaching. Available online: http://www.curee.co.uk/resources/publications/nationalframework-mentoring-and-coaching. (accessed on 18 August 2021).

33. Cordingley, P.; Buckler, N. Professional Learning Environments in Primary and Secondary Contexts; University of Manchester: Manchester, UK, 2012; pp. 11.00-12.30.

34. Fletcher, S.; Mullen, C.A. Sage Handbook of Mentoring and Coaching in Education; Sage: Thousand Oaks, CA, USA, 2012.

35. Perry, T.; Davies, P.; Brady, J. Using video clubs to develop teachers' thinking and practice in oral feedback and dialogic teaching. Camb. J. Educ. 2020, 50, 615-637. [CrossRef]

36. Brouwer, C. Equipping Teachers Visually; Stichting Kennisnet: Zoetermeer, The Netherlands, 2011.

37. Gaudin, C.; Chaliès, S. Video viewing in teacher education and professional development: A literature review. Educ. Res. Rev. 2015, 16, 41-67. [CrossRef]

38. Major, L.; Watson, S. Using video to support in-service teacher professional development: The state of the field, limitations and possibilities. Technol. Pedagog. Educ. 2018, 27, 49-68. [CrossRef]

39. Brouwer, N.; Besselink, E.; Oosterheert, I. The power of video feedback with structured viewing guides. Teach. Teach. Educ. 2017, 66, 60-73. [CrossRef]

40. Pehmer, A.-K.; Gröschner, A.; Seidel, T. How teacher professional development regarding classroom dialogue affects students' higher-order learning. Teach. Teach. Educ. 2015, 47, 108-119. [CrossRef]

41. Tripp, T.; Rich, P. Using video to analyze one's own teaching. Br. J. Educ. Technol. 2012, 43, 678-704. [CrossRef]

42. Lewis, C.; Perry, R.; Murata, A. How should research contribute to instructional improvement? The case of lesson study. Educ. Res. 2006, 35, 3-14. [CrossRef]

43. Davies, P.; Dunnill, R. 'Learning Study'as a model of collaborative practice in initial teacher education. J. Educ. Teach. 2008, 34, 3-16. [CrossRef]

44. Holmqvist, M. Teachers' learning in a learning study. Instr. Sci. 2010, 39, 497-511. [CrossRef]

45. Rich, P.J.; Hannafin, M. Video annotation tools: Technologies to scaffold, structure, and transform teacher reflection. J. Teach. Educ. 2009, 60, 52-67. [CrossRef] 
46. Van Es, E.A. Examining the development of a teacher learning community: The case of a video club. Teach. Teach. Educ. 2012, 28, 182-192. [CrossRef]

47. Borko, H.; Jacobs, J.; Eiteljorg, E.; Pittman, M.E. Video as a tool for fostering productive discussions in mathematics professional development. Teach. Teach. Educ. 2008, 24, 417-436. [CrossRef]

48. Kleinknecht, M.; Schneider, J. What do teachers think and feel when analyzing videos of themselves and other teachers teaching? Teach. Teach. Educ. 2013, 33, 13-23. [CrossRef]

49. Beisiegel, M.; Mitchell, R.; Hill, H.C. The Design of Video-Based Professional Development: An Exploratory Experiment Intended to Identify Effective Features. J. Teach. Educ. 2017, 69, 69-89. [CrossRef]

50. Seidel, T.; Stürmer, K.; Blomberg, G.; Kobarg, M.; Schwindt, K. Teacher learning from analysis of videotaped classroom situations: Does it make a difference whether teachers observe their own teaching or that of others? Teach. Teach. Educ. 2011, 27, 259-267. [CrossRef]

51. Jamil, F.M.; Hamre, B.K. Teacher Reflection in the Context of an Online Professional Development Course: Applying Principles of Cognitive Science to Promote Teacher Learning. Action Teach. Educ. 2018, 40, 220-236. [CrossRef]

52. Bates, M.S.; Phalen, L.; Moran, C.G. If you build it, will they reflect? Examining teachers' use of an online video-based learning website. Teach. Teach. Educ. 2016, 58, 17-27. [CrossRef]

53. Dede, C.; Eisenkraft, A.; Frumin, K.; Hartley, A. Teacher Learning in the Digital Age: Online Professional Development in STEM Education; Harvard Education Press: Cambridge, MA, USA, 2016.

54. Dana, N.F.; Pape, S.J.; Griffin, C.C.; Prosser, S.K. Incorporating practitioner inquiry into an online professional development program: The Prime Online experience. Prof. Dev. Educ. 2017, 43, 212-231. [CrossRef]

55. Owston, R.; Wideman, H.; Murphy, J.; Lupshenyuk, D. Blended teacher professional development: A synthesis of three program evaluations. Internet High. Educ. 2008, 11, 201-210. [CrossRef]

56. Theelen, H.; Van den Beemt, A.; den Brok, P. Classroom simulations in teacher education to support preservice teachers interpersonal competence: A systematic literature review. Comput. Educ. 2019, 129, 14-26. [CrossRef]

57. Billingsley, G.; Smith, S.; Smith, S.; Meritt, J. A systematic literature review of using immersive virtual reality technology in teacher education. J. Interact. Learn. Res. 2019, 30, 65-90.

58. Macià, M.; García, I. Informal online communities and networks as a source of teacher professional development: A review. Teach. Teach. Educ. 2016, 55, 291-307. [CrossRef]

59. Lantz-Andersson, A.; Lundin, M.; Selwyn, N. Twenty years of online teacher communities: A systematic review of formallyorganized and informally-developed professional learning groups. Teach. Teach. Educ. 2018, 75, 302-315. [CrossRef]

60. Saifuddin, K.M.; Strange, M.H. School teacher professional development in online communities of practice: A systematic literature review. In Proceedings of the 15th European Conference on e-Learning, Prague, Czech Republic, 27-28 October 2016; Academic Conferences International Limited: Reading, UK, 2016; pp. 605-614.

61. Frumin, K.; Dede, C.; Fischer, C.; Foster, B.; Lawrenz, F.; Eisenkraft, A.; Fishman, B.; Jurist Levy, A.; McCoy, A. Adapting to large-scale changes in Advanced Placement Biology, Chemistry, and Physics: The impact of online teacher communities. Int. J. Sci. Educ. 2018, 40, 397-420. [CrossRef]

62. Holmes, B. School Teachers' Continuous Professional Development in an Online Learning Community: Lessons from a case study of an e T winning Learning Event. Eur. J. Educ. 2013, 48, 97-112. [CrossRef]

63. Surrette, T.N.; Johnson, C.C. Assessing the ability of an online environment to facilitate the critical features of teacher professional development. Sch. Sci. Math. 2015, 115, 260-270. [CrossRef]

64. Keengwe, J.; Kang, J.-J. A review of empirical research on blended learning in teacher education programs. Educ. Inf. Technol. 2012, 18, 479-493. [CrossRef]

65. Lin, Q. Student satisfactions in four mixed courses in elementary teacher education program. Internet High. Educ. 2008, 11, 53-59. [CrossRef]

66. Goldenberg, L.; Culp, K.; Clements, M.; Anderson, A.; Pasquale, M. Online professional development for high-school biology teachers: Effects on teachers' and students' knowledge. J. Technol. Teach. Educ. 2014, 22, 287-309.

67. Tu, C.-H.; McIsaac, M. The relationship of social presence and interaction in online classes. Am. J. Distance Educ. 2002, 16, 131-150. [CrossRef]

68. Beatty, B.R.; Allix, N. Being there: Exploring extending and enriching distance education in real time with WebEx. In Proceedings of the Open and Distance Learning Association of Australia (ODLAA) Conference 2005, Adelaide, SA, Australia, 5-9 November 2005.

69. Subhash, S.; Cudney, E.A. Gamified learning in higher education: A systematic review of the literature. Comput. Hum. Behav. 2018, 87, 192-206. [CrossRef]

70. Qian, Y.; Hambrusch, S.; Yadav, A.; Gretter, S. Who Needs What: Recommendations for Designing Effective Online Professional Development for Computer Science Teachers. J. Res. Technol. Educ. 2018, 50, 164-181. [CrossRef]

71. Taylor, J.M. Characteristics of Effective Online Professional Development: A Case Study Analysis of an Online Professional Development Course Offered via Blackboard. Ph.D. Thesis, University of Pittsburgh, Pittsburgh, PA, USA, 2011.

72. Tella, A. Reliability and factor analysis of a blackboard course management system success: A scale development and validation in an educational context. J. Inf. Technol. Educ. Res. 2011, 10, 55-80. [CrossRef]

73. Thomas, T.S. Online vs. Face-to-Face: Educator Opinions on Professional Development Delivery Methods; University of Alabama Libraries: Tuscaloosa, AL, USA, 2010. 
74. Unwin, A. Developing new teacher inquiry and criticality: The role of online discussions. Br. J. Educ. Technol. 2015, 46, 1214-1222. [CrossRef]

75. West, R.E.; Rich, P.J.; Shepherd, C.E.; Recesso, A.; Hannafin, M.J. Supporting induction teachers' development using performancebased video evidence. J. Technol. Teach. Educ. 2009, 17, 369-391.

76. Timperley, H.; Wilson, A.; Barrar, H.; Fung, I. Teacher Professional Learning and Development. Best Evidence Synthesis iteration (BES); Ministry of Education: Wellington, New Zealand, 2007.

77. Robinson, V.M.; Hohepa, M.; Lloyd, C. School Leadership and Student Outcomes: Identifying What Works and Why; Australian Council for Educational Leaders: Winmalee, NSW, Australia, 2007; Volume 41, pp. 1-27.

78. Chen, N.-S.; Wei, C.-W.; Wu, K.-T.; Uden, L. Effects of high level prompts and peer assessment on online learners' reflection levels. Comput. Educ. 2009, 52, 283-291. [CrossRef]

79. Donnelly, R. Interaction analysis in a 'Learning by Doing'problem-based professional development context. Comput. Educ. 2010, 55, 1357-1366. [CrossRef]

80. Jarosewich, T.; Vargo, L.; Salzman, J.; Lenhart, L.; Krosnick, L.; Vance, K.; Roskos, K. Say what? The quality of discussion board postings in online professional development. New Horiz. Educ. 2010, 58, 118-132.

81. Prestridge, S. Teachers' talk in professional development activity that supports change in their ICT pedagogical beliefs and practices. Teach. Dev. 2009, 13, 43-55. [CrossRef]

82. Lauer, P.A.; Christopher, D.E.; Firpo-Triplett, R.; Buchting, F. The impact of short-term professional development on participant outcomes: A review of the literature. Prof. Dev. Educ. 2013, 40, 207-227. [CrossRef]

83. Allen, J.P.; Hafen, C.A.; Gregory, A.C.; Mikami, A.Y.; Pianta, R. Enhancing Secondary School Instruction and Student Achievement: Replication and Extension of the My Teaching Partner-Secondary Intervention. J Res. Educ. Eff. 2015, 8, 475-489. [CrossRef]

84. Kraft, M.A.; Hill, H.C. Developing Ambitious Mathematics Instruction Through Web-Based Coaching: A Randomized Field Trial. Am. Educ. Res. J. 2020, 57, 2378-2414. [CrossRef]

85. Pianta, R.; Hamre, B.; Downer, J.; Burchinal, M.; Williford, A.; Locasale-Crouch, J.; Howes, C.; La Paro, K.; Scott-Little, C. Early childhood professional development: Coaching and coursework effects on indicators of children's school readiness. Early Educ. Dev. 2017, 28, 956-975. [CrossRef]

86. Mashburn, A.J.; Downer, J.T.; Hamre, B.K.; Justice, L.M.; Pianta, R.C. Consultation for teachers and children's language and literacy development during pre-kindergarten. Appl. Dev. Sci. 2010, 14, 179-196. [CrossRef]

87. Early, D.M.; Maxwell, K.L.; Ponder, B.D.; Pan, Y. Improving teacher-child interactions: A randomized controlled trial of Making the Most of Classroom Interactions and My Teaching Partner professional development models. Early Child. Res. Q. 2017, 38, 57-70. [CrossRef]

88. Vernon-Feagans, L.; Bratsch-Hines, M.; Varghese, C.; Bean, A.; Hedrick, A. The Targeted Reading Intervention: Face-to-face vs. webcam literacy coaching of classroom teachers. Learn. Disabil. Res. Pract. 2015, 30, 135-147. [CrossRef]

89. Vernon-Feagans, L.; Kainz, K.; Hedrick, A.; Ginsberg, M.; Amendum, S. Live webcam coaching to help early elementary classroom teachers provide effective literacy instruction for struggling readers: The Targeted Reading Intervention. J. Educ. Psychol. 2013, 105, 1175. [CrossRef]

90. Landry, S.H.; Anthony, J.L.; Swank, P.R.; Monseque-Bailey, P. Effectiveness of comprehensive professional development for teachers of at-risk preschoolers. J. Educ. Psychol. 2009, 101, 448. [CrossRef]

91. Jackson, B.; Larzelere, R.; Clair, L.S.; Corr, M.; Fichter, C.; Egertson, H. The impact of HeadsUp! Reading on early childhood educators' literacy practices and preschool children's literacy skills. Early Child. Res. Q. 2006, 21, 213-226. [CrossRef]

92. Rosenberg, N.E.; Artman-Meeker, K.; Kelly, E.; Yang, X. The Effects of a Bug-in-Ear Coaching Package on Implementation of Incidental Teaching by Paraprofessionals in a K-12 School. J. Behav. Educ. 2020, 29, 409-432. [CrossRef]

93. Ascetta, K.; Harn, B.; Durán, L. Comparing Self-Reported and Performance-Based Online Feedback on Early Childhood Teachers' Implementation of Language Strategies. Early Child. Educ. J. 2019, 47, 353-365. [CrossRef]

94. Dash, S.; Magidin de Kramer, R.; O’Dwyer, L.M.; Masters, J.; Russell, M. Impact of online professional development or teacher quality and student achievement in fifth grade mathematics. J. Res. Technol. Educ. 2012, 45, 1-26. [CrossRef]

95. Fishman, B. Professional Development for the Redesigned AP Biology Exam: Teacher Participation Patterns and Student Outcomes; American Educational Research Association: Washington, DC, USA, 2014.

96. Griffin, C.C.; Dana, N.F.; Pape, S.J.; Algina, J.; Bae, J.; Prosser, S.K.; League, M.B. Prime online: Exploring teacher professional development for creating inclusive elementary mathematics classrooms. Teach. Educ. Spec. Educ. 2018, 41, 121-139. [CrossRef]

97. Shaha, S.H.; Ellsworth, H. Predictors of success for professional development: Linking student achievement to school and educator successes through on-demand, online professional learning. J. Instr. Psychol. 2013, 40, 19.

98. Shaha, S.H.; Glassett, K.F.; Copas, A. The impact of teacher observations with coordinated professional development on student performance: A 27-state program evaluation. J. Coll. Teach. Learn. (TLC) 2015, 12, 55-64. [CrossRef]

99. Shaha, S.; Glassett, K.; Copas, A.; Ellsworth, H. I Schools: The Student-Based Impact of Online, On-Demand Professional Development on Educators. Contemp. Issues Educ. Res. 2015, 8, 227-234. [CrossRef]

100. Shaha, S.; Glassett, K.; Copas, A.; Huddleston, T.L. Maximizing educator enhancement: Aligned seminar and online professional development. Contemp. Issues Educ. Res. (CIER) 2016, 9, 15-22. [CrossRef]

101. Shaha, S.H.; Glassett, K.; Copas, A. Sustaining Student Gains from Online On-Demand Professional Development. J. Int. Educ. Res. 2015, 11, 163-172. [CrossRef] 
102. Shaha, S.H.; Glassett, K.F.; Ellsworth, H. Long-term impact of on-demand professional development on student performance: A longitudinal multi-state study. J. Int. Educ. Res. (JIER) 2015, 11, 29-34. [CrossRef]

103. Walker, A.; Recker, M.; Ye, L.; Robertshaw, M.B.; Sellers, L.; Leary, H. Comparing technology-related teacher professional development designs: A multilevel study of teacher and student impacts. Educ. Technol. Res. Dev. 2012, 60, 421-444. [CrossRef]

104. Weschke, B.; Barclay, R.D.; Vandersall, K. Online Teacher Education: Exploring the Impact of a Reading and Literacy Program on Student Learning. J. Asynchronous Learn. Netw. 2011, 15, 22-43. [CrossRef]

105. Fisher, J.B.; Schumaker, J.B.; Culbertson, J.; Deshler, D.D. Effects of a Computerized Professional Development Program on Teacher and Student Outcomes. J. Teach. Educ. 2010, 61, 302-312. [CrossRef]

106. Fishman, B.; Konstantopoulos, S.; Kubitskey, B.W.; Vath, R.; Park, G.; Johnson, H.; Edelson, D.C. Comparing the Impact of Online and Face-to-Face Professional Development in the Context of Curriculum Implementation. J. Teach. Educ. 2013, 64, 426-438. [CrossRef]

107. Rock, H.M. The Effect of Face-to-Face versus Online Pedagogy-Based Professional Development on Student Learning Outcomes; Grand Canyon University: Phoenix, AZ, USA, 2017.

108. Webb, D.C.; Nickerson, H.; Bush, J.B. A Comparative Analysis of Online and Face-to-Face Professional Development Models for CS Education; Association for Computing Machinery: New York, NY, USA, 2017; pp. 621-626.

109. Russell, M.; Carey, R.; Kleiman, G.; Venable, J.D. Face-to-face and online professional development for mathematics teachers: A comparative study. J. Asynchronous Learn. Netw. 2009, 13, 71-87. [CrossRef] 